\title{
Assessing mortality registration in Kerala: The MARANAM Study
}

\author{
Aashish Gupta* Sneha Sarah Mani*
}

October 21, 2021

\begin{abstract}
Complete or improving civil registration systems in sub-national areas in low- and middle-income countries provide several opportunities to better understand population health and its determinants. In this article, we provide an assessment of vital statistics in Kerala, India. Kerala is home to more than 33 million people and is a comparatively low-mortality context. We use individual-level vital registration data on more than 2.8 million deaths between 2006 and 2017 from the Kerala MARANAM (Mortality and Registration Assessment and Monitoring) Study. Comparing agespecific mortality rates from the Civil Registration System (CRS) to those from the Sample Registration System (SRS), we do not find evidence that the CRS underestimates mortality. Instead, CRS rates are smoother across ages and less variable across periods. In particular, the CRS records higher death rates than the SRS for ages where mortality is usually low and for women. Using these data, we provide the first set of annual sex-specific life tables for any state in India. We find that life expectancy at birth was 77.9 years for women in 2017 and 71.4 years for men. Although Kerala is unique in many ways, our findings strengthen the case for more careful attention to mortality records within low- and middle-income countries, and for their better dissemination by government agencies.
\end{abstract}

*Gupta (aashishgupta@hsph.harvard.edu), Harvard University \& Mani (sneham@sas.upenn.edu), University of Pennsylvania. Both authors made equal contributions. We thank Apurva Bamezai, Jere Behrman, Pritha Chatterjee, Amanda Cheong, Diane Coffey, Nafissatou Diop, Irina Dincu, Irma Elo, Everton Emanuel, Michel Guillot, Patrick Gerland, Payal Hathi, Devesh Kapur, Ridhi Kashyap, Bruno Masquellier, Paul Monet, Chalapati Rao, Philip Setel, Kanika Sharma, Abhishek Shaw, Romesh Silva, Nikkil Sudharsanan, Atheendar Venkataramani, and Sangita Vyas for many helpful suggestions. We are grateful to Sai Ankit Parashar for excellent research assistance. For clarifications on Kerala's Civil Registration System, we are grateful to TK Jose, Misha SV, and Rajesh. This work was supported by an IUSSP CRS fellowship, summer travel funds from the Center for Advanced Study of India, and research funding by the research institute for compassionate economics. The IUSSP CRS fellowship program is made possible with financial support from the Centre of Excellence for Civil Registration and Vital Statistics Systems, housed at the International Development Research Centre (IDRC). 


\section{Introduction}

Records of births and deaths are among the most important statistics that states and societies collect and maintain (Szreter \& Breckenridge, 2012). Reliable mortality registration systems help individuals access social and governmental resources, provide timely information to monitor health, and generate essential data to evaluate the determinants of mortality (AbouZahr et al., 2015). These records are the basis of life table databases for high-income countries, such as the Human Mortality Database (Barbieri et al., 2015). Mortality registration, however, is incomplete in many low- and middle-income countries (AbouZahr, Rampatige, Lopez, \& de Savigny, 2012). In these cases, the systems miss many vital events, biasing mortality estimates downward (Mathers, Ma Fat, Inoue, Rao, \& Lopez, 2005).

The unreliability and incompleteness of mortality registration in developing countries has motivated demographers to develop and use indirect or survey-based approaches for estimating mortality levels (Department of International Economic and Social Affairs, 1983; Hill, 1991; Moultrie et al., 2013; Timaeus, 1991). These approaches include estimating mortality rates from a) survival of relatives - often siblings or parents (Brass, 1975; Feehan \& Borges, 2019; Masquelier, 2013; Masquelier et al., 2020; Saikia, Bora, \& Luy, 2019; Timæus \& Jasseh, 2004); b) survival in a network (Feehan, Mahy, \& Salganik, 2017); c) inferring mortality from observed age patterns between censuses (Hill, You, \& Choi, 2009); or d) from model age patterns of mortality (Clark, 2019; Murray et al., 2003; Wilmoth, Zureick, Canudas-Romo, Inoue, \& Sawyer, 2012). Many countries have also initiated representative and continuous sample registration exercises (Amouzou et al., 2020; Bhat, 2002; Liu et al., 2016; Setel et al., 2005). One such exercise, the Sample Registration System, has been functional in India since the late 1960s, and annual reports have been published since 1971 (Bhat, Preston, \& Dyson, 1984; Mahapatra, 2017).

Recent evidence suggests that vital registration has also been improving in develop- 
ing countries (Garenne et al., 2016; G. A. Kumar, Dandona, \& Dandona, 2019; Rao \& Gupta, 2020). India's Registrar General estimated that about 86 percent of all deaths in the country were registered in 2018 (A. Gupta, 2020; Banaji \& Gupta, 2021). This is the last year for which civil registration reports have been compiled and released. Based on this comparison with the crude death rates in the SRS, ORGI (2020) notes that civil registration was complete in 15 out of 36 states and union territories in India.

Mortality records from areas where civil registration is complete provide several opportunities to improve the evidence base for population health. First, examining how these regions improved registration can provide motivation and strategies for similar regions to improve their vital registration systems. Second, these studies may identify key areas where vital statistics systems can still be improved within the region under study. Third, if mortality records are reliable, and if cause-of-death data are available, these data can serve as the default data for public health surveillance, guiding health policy. Fourth, they provide an impetus for similar evaluations in sub-national areas where mortality registration is complete. Finally, these records may even displace intermittent surveys and indirect estimates and, at the very least, help understand limitations and strengths of alternative demographic estimation techniques.

Building on this perspective, this paper examines mortality estimates from the Civil Registration System (CRS) in Kerala, India. We obtained anonymized records for all deaths registered in Kerala for the years 2006 to 2017. The death records we obtained contain information on more than 2.8 million deaths. We use estimated population exposures from the DHS Program (2020) for Kerala for this period to estimate age-specific mortality rates. We are able to make three key contributions using these data.

First, we examine the reliability and completeness of death registration in Kerala. We focus on comparisons of overall crude death rates between the Civil Registration System (CRS) and the Sample Registration System (SRS); the extent of missing information on 
age and sex among registered deaths in the CRS; age misreporting among deaths; comparing female and male mortality rates; and comparisons over time. Our findings suggest improvements in the CRS between 2006 and 2017.

Second, we calculate age-specific mortality rates for the years 2006 to 2017 using mortality records from the CRS and population estimates from the 2011 Indian census and population projections. Previous studies from India's CRS have been constrained because annual reports from the CRS publish death counts by broad age groups $(0-1,1-4$, 5-14, 15-24, 25-34, 35-44, 55-64, 65-79, 80+). This necessitates approximations for death counts in abridged life table ages, as done by (Rao \& Gupta, 2020). Access to microdata allows us to compare civil registration system age-specific mortality rates in abridged life table ages to those observed by the SRS. This comparison helps us understand if mortality registration varies by age and sex, and the extent to which concerns about the reliability of the SRS are true in Kerala (Bhat, 2002; Rajan \& Mohanachandran, 1999; Saikia, Singh, \& Ram, 2010). We find that mortality rates generated using the civil registration system show less year-to-year variation than the SRS and are smoother across the adult ages.

Third, we also compare unadjusted mortality rates in single age years computed using census population estimates for 2011 with Gompertz mortality rates in ages 40 to 90 . We find very close correspondence between unadjusted and Gompertz mortality rates.

Finally, using these data, we provide the first set of directly estimated annual abridged life tables, to our knowledge, for any state in India. We compile these life tables for 2011 to 2017, the years for which we are able to conduct tests on the robustness of the data.

In the next section, we provide background information on Kerala and the CRS. In the "Materials and methods" section, we discuss the data and estimation methods in detail. We provide our main results and robustness checks thereafter. We conclude with a discussion of the main strengths and weaknesses of these data, suggestions for their better dissemination and further improvement, and, finally, their implications for demographic 
estimation in low- and middle-income countries.

\section{Background}

A state in south India, Kerala is home to more than 33 million people (Government of India, 2011). Although it is a state in India, Kerala's population is surpassed by only 42 countries in the world. Its population is also greater than that of 30 countries and areas for which the Human Mortality Database (HMD) makes available life tables (out of a total of 41 HMD countries and areas) (Barbieri et al., 2015; United Nations, 2019b). Kerala's human development achievements have been widely noted and celebrated (Sen, 2001). It has been an important example within the "routes to low mortality in developing countries" framework (Balabanova et al., 2013; Caldwell, 1986; Kuhn, 2010) and is the state with the highest life expectancy in India (Office of the Registrar General and Census Commissioner of India, 2018). Given these achievements, Kerala's experience has been important in governance, health, and development policy discussions in India and elsewhere (Heller, 2006; Ramachandran, 1997).

These human development and governance achievements are reflected in Kerala's CRS as well. Annual reports based on the civil registration system (Office of the Registrar General and Census Commissioner of India, 2013) classify civil registration in Kerala as "complete." ${ }^{1}$ Recently released summary findings from the fifth round of the National Family Health Survey reinforce these results. ${ }^{2}$ Noting these "high levels of registration" in Kerala, James et al. (2013) argued that "this calls for detailed records of civil registration."

Within the Government of Kerala administration, the Department of Economics and Statistics and the Department of Local Self-Government maintain the CRS in the state. Civil registration is governed by the Registration of Births and Deaths Act, 1969 and the 
Kerala Registration of Births and Deaths Rules 1999. The 1999 rules were updated after an initial set of rules in 1970. The departments maintain an IT system to record births, deaths, and marriages, called Sevana. The Information Kerala Mission developed this computerized data entry system for civil registration, which started registering births and deaths in 2000 (Government of Kerala, 2008). In the early 2000s, local registration authorities shifted completely to the online system. The Information Kerala Mission organized efforts to enter data from vital records that were not computer recorded. By 2006, all local registrars were using the computerized system for recording vital deaths. In their annual reports, the CRS describes several steps that they take to monitor the quality and completeness of vital statistics. These include spot checks and audits of registrars, checking and following up on data entry errors, and nominal fines for late registration of vital events. A total of 1035 units in the state registered vital events - 941 units in rural areas and 94 units in urban areas (Government of Kerala, 2020).

We present preliminary evidence in Figure 1 that suggests that the new rules and computerization improved the CRS in Kerala. The figure shows crude death rates from two sources - the CRS and the SRS. ${ }^{3}$ Although higher mortality estimates are not necessarily truer mortality estimates, comparisons from different sources are often used to judge the reliability of mortality reporting (Brown, Lariscy, \& Kalousová, 2019; Preston, Heuveline, \& Guillot, 2001). Comparisons with the crude death rates observed in the SRS is also the official method used by India's Registrar General to assess the completeness of death registration (Office of the Registrar General and Census Commissioner of India, 2013). The comparison here for Kerala shows that until the early 2000s, Kerala's CRS underestimated mortality compared to the SRS. However, starting in the year 2004, and until about 2012, overall mortality rates in Kerala's CRS were similar to those in the SRS. ${ }^{4}$ More recently, Kerala's CRS has recorded more deaths than the number of deaths estimated by the SRS. This suggests that the SRS may be under reporting mortality in Kerala and reinforces the suggestion by James et al. (2013) that the CRS may be a useful source to examine mortality 
levels from individual-level mortality records. ${ }^{5}$

\section{Materials \& methods}

The section below describes these mortality data, part of the Kerala Mortality and Registration Assessment and Monitoring (MARANAM) Study, the population exposures we use to calculate mortality rates, and our analytical strategy.

\section{Data}

\section{Mortality records}

We obtained anonymized individual-level death records from the Department of Economics and Statistics and the Department of Local Self-Government in the Government of Kerala in 2019. Because some records before 2006 are scanned documents which are not machine readable, the Department of Local Self-Government made available death records starting in 2006. The last year for which these records were made available was 2017. These data were anonymized by the Department of Local Self-Government. The data contain information on year of death; age at death; sex of the deceased person; whether the registration authority is a municipal corporation, a municipality, or a panchayath (local self-government body in rural areas); the district where the death was registered; and the state where the deceased person's permanent address is located. We did not obtain any identifying details for any of the deaths that were registered.

This study uses death records and is consequently exempt from review by the Institutional Review Board because it does not meet the regulatory definition of human subjects research, as noted in 45 CFR Protection of Human Subjects 46.102(e) (in effect on December 22, 2020). According to the U.S. Department of Health and Human Services and Food 
and Drug Administration regulations, if none of the individuals in a study are alive, it does not involve a human subject and does not require review (US Department of Health and Human Services and others, 2020). We obtained permission to analyze these data and report their results from the Department of Economics and Statistics and the Department of Local Self-Government in the Government of Kerala (dated July 23, 2019). These data are available, on request, directly from these departments.

\section{Estimates for population exposures}

To calculate life tables and age-specific mortality rates, we use annual counts of population in five-year age groups estimated by Leddy Jr (2016). These estimates were created by the U.S. Census Bureau for the U.S. PEPFAR program, and are available from the DHS Program Spatial Data Repository (DHS Program, 2020). We adjust these population counts by estimating the $0-1,1-4,80-85$, and $85+$ population to calculate abridged life tables. To do this, we use the estimated population from the 2001 census, the 2011 census, the SRS, and 2016 estimates from India's official population projections (National Commission on Population, 2019). These sources provide the proportion of 0-5 (or 80+) age group populations within the $0-1$ and $1-4$ (or the $80-85$ and $85+$ ) age groups for the years 2001, 2011, and 2016. For years when these estimates are not available, we use a cubic spline interpolation. Thus, for each year in 2006 to 2017, we obtain estimates of total population by sex in the age groups $0-1,1-4,5-10,10-15$, and so on, till $80-85$, and $85+$.

We check if our results are robust to using alternative sources of population estimates. For this, we compare age-specific mortality rates using the population exposures described above to age-specific mortality rates calculated using the 2011 census estimates and the 2016 population estimates from India's official population projections, estimated by the National Commission on Population (2019). 


\section{Other estimates}

To assess the reliability of age-specific mortality rates calculated from CRS, we compare these estimates to those from the SRS. The SRS is a continuous survey that has been monitoring vital events in a representative panel of villages and urban blocks since 1971 (RGI, 2016; Mahapatra, 2017). The SRS panel was revised in in 1977-78, 1983-85, 1993-95, 2004, and 2014 (Dreze, Gupta, Parashar, \& Sharma, 2020; ORGI, 2016). ${ }^{6}$ When the SRS panel was revised in 2014, it visited 280 sample units, covering a population of 368,000 . In the 2004 revision, the number of sample units was 250, covering a population of 330,000. For comparisons, we created machine readable copies of annual reports from the SRS. We also derive ${ }_{n} a_{x}$ (average person years lived by those who died) values from the five-year period abridged life tables released by the SRS (Office of the Registrar General and Census Commissioner of India, 2018). For some estimates, such as infant mortality rates and crude death rates for some years for which annual reports were not available online, we used the SRS compendium publication (RGI, 2016). Although the SRS is a survey, stan-

dard errors and 95 percent confidence intervals for age-specific mortality rates are not released by the SRS.

In addition to the SRS, we use information from the annual vital statistics reports published by Kerala's Department of Economics and Statistics (Government of Kerala, 2019). We compute infant mortality rates in ages $0-1$ from the fourth round of India's Demographic and Health Surveys (2015-2016). For robustness checks and comparisons, we also use mortality records from the Human Mortality Database (Barbieri et al., 2015).

\section{Analytical strategy}

Our analytical strategy consists of the following steps. First, we compute crude death rates from the CRS and compare them to the crude death rates from the SRS, examine 
trends in the proportion of deaths that were missing information on age or sex, and study the severity of age heaping using the Myers blended index and the Whipple index.

In the next step, we compute age-specific death rates from the CRS mortality records and population exposures estimates. We compare these age-specific death rates to those observed by the SRS. Although a variety of methods have been proposed in the literature to infer completeness of civil registration (Hill et al., 2017), we focus on comparisons with the SRS because this requires fewer assumptions and is more empirical than other methods (D. Glei, Paz, Aburto, \& Barbieri, 2021).

After this step, we use standard life table methods (Preston et al., 2001) to estimate abridged life tables by sex and calendar-year for the state of Kerala using the CRS agespecific mortality rates. ${ }^{7}$

In robustness tests, we calculate mortality estimates using alternative population exposures; compare infant mortality estimates from the SRS, National Family Health Surveys (NFHS), and CRS; compare unadjusted and Gompertz mortality rates in single-year ages 40 to 90; examine the extent to which migration can bias estimates from the CRS; and, following D. A. Glei, Barbieri, and Santamaría-Ulloa (2019), compare the relationship between child mortality and old-age mortality for Kerala and the Human Mortality Database countries.

\section{Results}

\section{Summary statistics for the MARANAM study}

Table 1 presents summary statistics for these individual-level mortality data for the years 2006 to 2017. It shows annual statistics for observed deaths, crude death rates, and the proportion of deaths with missing information on either age or sex. We show observed 
deaths and estimated crude death rates by year for males, females, and the overall population. The number of deaths observed in Kerala have been increasing, especially in the late 2000s. This could be because of improvements in civil registration but also because of populating aging and past population growth (United Nations, 2019b). Although the SRS crude death rates show greater fluctuations (Figure 1), increasing crude death rates can be observed in both the CRS and SRS.

Comparing across gender, female crude deaths rates are lower than male crude death rates in the CRS. This is expected: the SRS also observes vast differences in life expectancy estimates between women and men in Kerala, and these observed death counts could largely be a function of mortality differences rather than reporting differences. Still, the female crude death rate in 2006 was estimated to be 5.3 deaths per 1,000, which is lower than other years, suggesting some underreporting of deaths. This could be because this was the first year in which all deaths were supposed to be recorded in the newer computerized CRS.

It is worth noting that the proportion of deaths in which age or sex was missing declined. In 2006, this proportion was 2.0 percent of all deaths registered. By 2017, it had declined to about 0.3 percent of all deaths. This reflects improvements in mortality recording. We provide more detailed patterns on missing information in Appendix Table A1.

\section{Comparison of age-specific mortality rates in the civil and sample regis- tration systems}

We calculate age-specific mortality rates for the years 2006 to 2017 from the CRS and compare them to those reported by SRS in its annual reports. These comparisons can be seen in Figures 2 and 3. ${ }^{8}$ The figures, which are on the log scale, show that age-specific mortality rates from the SRS are less smooth than those estimated from the CRS. In contrast to 
the SRS, the CRS estimates follow expected age patterns of mortality and fluctuate less. A part of the explanation for less smooth estimates in the SRS is that it is a sample. Because the SRS does not publish standard errors of its estimates, we are unable to account for the uncertainty in the SRS estimates. We note that the problems are more severe for women and at younger ages. In some ages, and for some years, age-specific mortality rates in the SRS are very low. A notable exception is the year 2014. The SRS panel was revised in 2014, and mortality rates in the SRS are higher for women than those observed in the CRS. This is not the case for SRS rates for men in 2014.

It is worth noting that CRS estimates reflect expected age patterns of mortality for all years, even in the beginning of the study period. On the other hand, underestimation of mortality in the SRS is increasing within this period. Indeed, SRS estimates fluctuate more in recent years. ${ }^{9}$

In Appendix Figures A5 and A6, we compare three-year average, five-year average, and abridged life table (which are for five-year periods) age-specific mortality rates from the SRS to corresponding CRS rates. Pooling across years in the SRS does reduce fluctuations across ages. However, mortality in some ages, such as between ages 5 and 9 for males, may still be too low in the SRS. In Appendix Table A10, we quantify year-to-year variation in the CRS and SRS age-specific mortality rates. In ages $0-1$ and $85+$, variation in the CRS and the SRS can be considered similar. For all other ages, variation in the SRS is much higher than in the CRS, likely driven by sampling variability in the SRS.

One age group where mortality rates between the SRS and the CRS differ substantially is below age 1. We examine these differences in greater detail in the "Robustness" section below, which includes comparisons with the National Family Health Survey-4 in India. More research is needed to understand these differences.

What are the overall implications of the comparison of age-specific mortality rates between the SRS and the CRS? One interpretation is that these findings are contrary to 
the expectation that civil registration systems in developing countries necessarily perform worse than other mortality monitoring systems, such as survey-based estimates from sample registration systems. These comparisons reveal a need for careful assessment of mortality estimates from the SRS, as well as of associated studies, such as those examining causes of death based on verbal autopsies of deaths recorded by the SRS.

\section{Life table estimates}

Table 2 provides estimates for age-specific probabilities of death between ages $0-15$, ages $15-60$, and $60-85$ by year. Mortality rates have declined in the child and adult ages, especially when comparing estimates from 2007 to 2017. Patterns of older age mortality are more complicated, with no clear trends. This may be driven by age misreporting and variation in registration of deaths. Probability of death for all ages was lower in 2006 compared to 2007, especially in the adult and older ages. This may be because of underreporting of deaths in 2006.

Table 3 provides life expectancy estimates for the years 2011 to 2017. We report the full set of life tables for these years in Appendix tables A2 - A8. Consistent with the SRS, female life expectancy at birth is much higher than male life expectancy for 2006 to 2017. These patterns can be seen across the life course. Surprisingly, life expectancy estimates for 2017 are lower than those of other recent years. Appendix Figure A2 also notes an increase in the infant mortality rate for 2017 in the CRS. These patterns may reflect true mortality increases, given the large scale increase in poverty and unemployment in India following the demonetization in India in November 2016 (Dreze et al., 2020). 


\section{Robustness}

\section{Comparison of infant mortality rates}

A pattern that can be noticed in Figures 2 and 3 is that mortality rates below age 1 in the SRS are higher than those observed in the CRS. To investigate this, we compare mortality rates in the SRS, CRS, and the fourth round of the National Family Health Survey (NFHS) in Appendix Figure A2. ${ }^{10}$ NFHS and CRS rates show declines over time, whereas SRS age-specific mortality rates fluctuate much more and increase substantially between 2008 and 2015. It is likely that these fluctuations would be less severe if the SRS were to visit a larger number of clusters.

Additionally, NFHS mortality rates for infant girls are very close to those in the CRS, while rates for infant boys in the NFHS are between the CRS and the SRS. The SRS shows lower mortality among boys than among girls. In contrast, mortality among boys compared to girls is higher in the NFHS and the CRS. This is confirmed by Figure A3. Infant mortality rates for females are observed to be lower than those of boys across contexts (Alkema, Chao, You, Pedersen, \& Sawyer, 2014; Sawyer, 2012). Although this is not true across India, Kerala is a notable outlier in the Indian context (Sen, 2001), with females enjoying higher status compared to other states. In light of this, patterns in the NFHS and CRS are more likely to be true than those in the SRS. Recently released NFHS-5 state fact sheets do have information on sex-specific probability of dying by age 1. Still, they note that overall infant mortality $\left({ }_{1} q_{0}\right)$ in the period $2014-2019$ to be 4.4 deaths per 1,000 births (Varghese, Gupta, Mehta, Stein, \& Patel, 2021). This is the same level of mortality below age 1 in the CRS and is much lower than that of the SRS.

We note that there are some unexplained patterns in the CRS as well. There is an unexplained rise in mortality among girls in 2012, which is not seen for boys. Reasons for this are not clear. According to the CRS, infant mortality also increased slightly in 
2017 compared to 2016. This, however, is similar to patterns found elsewhere by Dreze et al. (2020) and may be due to the income and employment shocks induced by India's demonetization experiment. ${ }^{11}$ When further data is available, such as from NFHS-5, it would be helpful to understand infant mortality in Kerala.

\section{Alternative population exposures}

To what extent are these estimates driven by problems with underlying exposures, rather than mortality? Appendix Figures A7 and A8 examine the implications of alternative population exposures. In Appendix Figure A7, census-based age-specific mortality rates are calculated by using deaths in the period from September 1, 2010 to August 31, 2011 in the numerator and Census 2011 population as on March 1, 2011 in the denominator. In Figure A8, we use the 2016 population as estimated by National Commission on Population (2019) for comparison. Both figures reveal that using alternative population exposures changes estimated mortality rates slightly, but does not alter any of the substantive conclusions drawn here.

\section{Age heaping}

Figure A9 and Figure A10 describe the age distribution of deaths in single age years for females and males respectively. These figures show a high-degree of age heaping, even in a universal literacy context. However, age heaping has been declining over time, as can be observed in less sharp peaks in later years.

To systematically assess the extent of age heaping and digit preference, we report the Myers blended index and Whipple index. The Myers index considers preference of ages ending in each of the digits 0 to 9 . The index ranges from 0 to 90 , with 0 corresponding to no age heaping and 90 corresponding to extreme age heaping. Whipple's age heaping 
index indicates the preference of ages ending in 0 or 5 for ages between 23 and 62. The index ranges from 100 to 500, with 100 indicating no digit preference in age reporting while 500 corresponds to all reported ages ending in digits 0 or 5 . Figure A11 reports these indices. We observe a downward trend for the indices between 2006 and 2017, indicating that over time, there is a fall in digit preference in ages reported during death registration. The digit preference in reported ages is higher for females than males, but the gap has reduced over time. For recent years, age heaping in deaths registered in Kerala is less severe than the age heaping reported in the Indian census in 2011 (United Nations, 2019a). ${ }^{12}$

\section{Comparison with Gompertz mortality rates}

Given age misreporting in both population and death counts, to what extent are the life expectancy estimates at older ages biased? Although they are affected by age misreporting, Figures 2 and 3 show that broadly, mortality in the abridged life table ages increases exponentially in the adult ages for the mortality rates estimated using the CRS. However, using abridged life table ages masks considerable age heaping, as reported in the section above. To understand the extent to which age misreporting in single ages affects life expectancy estimates, we compute Gompertz mortality rates using single age population counts from the 2011 census and deaths in single ages from the CRS data. The results of this comparison are shown in Appendix Figure A12.

Each panel in Figure A12 shows estimates for females and males. The top-left panel shows mortality rates, the top-right panel shows survivors to age $x$, the bottom-left panel shows life table deaths, and the last panel shows estimated life expectancy. Together, the panels show that even with substantial age heaping and misreporting of ages, unadjusted life expectancy estimates are very close to life expectancy estimates from predicted mortality rates using a Gompertz function. In practice, our mortality rates are less affected 
by age misreporting than the ones reported here, because we use five-year age intervals. Even then, the similarity of unadjusted and Gompertz life expectancy estimates in single ages and up to age 90 is reassuring. ${ }^{13}$

\section{Comparison of the relationship between child and older age mortality}

Following D. A. Glei et al. (2019), Appendix Figure A14 plots the relationship between child mortality ${ }_{5} q_{0}$ and older age mortality ${ }_{20} q_{60}$ for Kerala (2006 to 2017) and all populations available in the Human Mortality Database (HMD) for the period 1971 to 2017. Among older adults, the HMD estimates are clustered along a line connecting the upper right (high child and old age mortality) and lower left quadrants (low child and old age

mortality). Given ${ }_{5} q_{0}, 20 q_{60}$ estimates for Kerala are at levels similar to those of the HMD countries and areas. These comparisons suggest that the possibility of biases in levels of ${ }_{5} q_{0}$ or ${ }_{20} q_{60}$ in Kerala is relatively low. Appendix Figure A13 shows these patterns for adult and child mortality. It also finds that patterns observed in Kerala are not anomalous when compared to the HMD.

\section{Migration}

We include a discussion of how migration may affect the mortality rates in the Supplementary Appendix. Briefly, because Kerala is a high-migration context (Rajan \& Zachariah, 2019), it is important to consider it in a mortality analysis. However, data constraints do not permit a full accounting of how mortality among in- and out-migrants affects estimates here. In the Statistical Appendix, we show that deaths among out-migrants outside Kerala are likely a minuscule fraction of overall deaths. We also use existing data to investigate how the crude death rate will change if migration is accounted for. We find these changes to be small. We note that a careful accounting of how migration affects 
mortality rates would also warrant an assessment of usual residence status in Kerala for both deaths and population. This information is not available right now.

\section{Discussion}

Using vital statistics death records, this article provides the first set of age-specific mortality rates and abridged life tables by year and sex for any state in India. The article extends the existing literature on civil registration in India (M. Gupta, Rao, Lakshmi, Prinja, \& Kumar, 2016; Rao \& Gupta, 2020), which has been constrained by the unavailability of death counts in abridged life table age groups in CRS summary reports. We document a large sex difference in mortality, with much lower life expectancy for men than for women, which is important to understand from a public health perspective. More broadly, the article shows that just as there are routes to low mortality in developing country contexts (Caldwell, 1986; Kuhn, 2010), reliable and complete civil registration systems within developing countries do exist. In addition to mortality estimation, these systems are critical from a human rights perspective, because they help people access their basic rights (Bhatia, Krieger, Beckfield, Barros, \& Victora, 2019; Szreter \& Breckenridge, 2012).

The article demonstrates that the CRS in Kerala records more deaths than those estimated by the SRS. It raises other concerns about the current functioning of the SRS as well. Age-specific mortality rates from the CRS are smoother for annual periods than those estimated by the SRS. This suggests that an increase in the overall sample size of the SRS, as well as an increase in the number of clusters it visits, is necessary for reliable annual estimates. We note a discrepancy in mortality rates below age 1 between the SRS, the CRS, and the NFHS, which needs further investigation. More transparency from the SRS and public release of its microdata are essential to understanding these discrepancies.

In robustness checks, we show that mortality estimates from the CRS are robust to 
alternative estimates for populations exposed to the risk of death, that accounting for migration will not change the results reported here substantially, and that age heaping and misreporting have been declining in the CRS in Kerala. Age heaping may still be influencing mortality estimates (Gerland, 2014), particularly at older ages (Preston, Elo, \& Stewart, 1999). In this article, we have preferred empirical estimates over smoothing techniques, largely because simpler and intuitive estimation techniques are more likely to be adopted by civil registration authorities. These authorities often lack technical expertise or resources for more complicated analyses on a routine basis. Still, we show that smoothed mortality rates using a Gompertz model predict similar levels of mortality as unadjusted rates. Overall, the analysis here reinforces conclusions drawn in Rao and Gupta (2020): that the CRS can be used to monitor trends and determinants of mortality reliably in some contexts within India.

We note that these data and our analyses have some limitations. For some of the earliest years for which this data is available, mortality probabilities are slightly lower compared to later years. Given that there are no identified reasons to expect an increase in mortality in this period, particularly between 2006 and 2007, estimates for earlier years likely underestimate mortality. There are also a higher number of deaths with missing information on age and sex in the years 2006 to 2010. This suggests more careful use of data for these years. We recommend that data from these earlier years (such as before 2011) should largely be ignored in mortality analyses, particularly for analysis of trends. These data may still be valuable for understanding determinants of health, but conclusions drawn from these years may be tentative. Other discrepancies, such as an increase in infant mortality among girls in 2012, also deserve more scrutiny.

From the perspective of improving the CRS in Kerala, the article identifies several priorities. Within Kerala, these data and their properties deserve greater attention than they currently receive. Although government agencies prepare an annual report based on 
these data, they are not used to estimate life expectancies or understand the determinants of mortality. ${ }^{14}$ In this, there is a case for improving capacity within government agencies to make fuller use of these data (Bhatia, Victora, Beckfield, Budukh, \& Krieger, 2021).

During the ongoing COVID-19 pandemic, civil registration data from Kerala did not find excess mortality in 2020 (Government of Kerala, 2021). This is partly because the scale of additional mortality in Kerala was not that high in 2020 and partly because of delays in registration of deaths (A. Gupta, Rukmini, \& Rajendran, 2021). For 2021, however, Kerala's CRS did record more deaths than expected: excess mortality was even greater than the reported COVID-19 death toll in the state (A. J. Kumar, 2021; Rajendran \& Kurian, 2021; Ramani, 2021). These data have informed both local and comparative perspectives on COVID-19 mortality. The magnitude of excess mortality in Kerala is lower than other Indian states where such data is available, likely reflecting better management of the pandemic within the state (Banaji \& Gupta, 2021). They have also bolstered calls within the state to better monitor and address the mortality burden. Moving forward, if these data are released, they can inform scientific and policy questions about mortality impact, spread, and age gradient.

In terms of reforms within the system, annual reports from vital registration systems at both the state and the national levels currently summarize data on deaths in broad age categories (0-1, 1-4, 5-14, 15-24, 25-34, 35-44, 45-54, 55-64, 65-79, and 70+). Ideally, annual reports should consider displaying death counts and mortality rates by abridged life table ages, going up to age 85 . These reports are also compiled after much delay. ${ }^{15}$ Increased capacity in compiling these reports and releasing them sooner will also help serve the goals of public health surveillance. The analyses presented here build a case for further use of these data to understand the distribution and determinants of health in Kerala. The CRS in Kerala may also allow for finer estimates of mortality, such as at the district level; understanding the quality of cause-of-death reporting, and, if reliable, 
comparisons based on verbal autopsy based studies; and understanding social patterns, such as by gender and religion. Unlike other Indian administrative systems, the CRS does not currently collect information on caste and Indigenous status. Given that these are important determinants of population health in India (A. Gupta \& Sudharsanan, 2020; Ramaiah, 2015; Vyas \& Hathi, 2021), reforms in civil registration should prioritize collecting this information.

The analyses here also have implications for research on civil registration and mortality estimation in developing countries in general, as well as implications specific to Kerala and the Indian context. The analysis here supports efforts to reduce reliance on modeled estimates, which have considerable uncertainty (Rao, Gupta, Gupta, \& Yadav, 2021). Kerala's experience in improving Civil Registration System may be helpful for other states in India in improving their civil registration systems. For this, there is a greater need for qualitative research on vital statistics systems. More broadly, the research here makes a case for much greater engagement with vital statistics systems in low- and middle-income country contexts.

\section{Notes}

${ }^{1}$ This comparison is based on comparing crude death rates from the Civil Registration System (CRS) with those from the SRS (SRS).

${ }^{2}$ National Family Health Survey (NFHS)-5, in 2019-20, asked a question on the deaths in the household in the last three years. For previous rounds, this question has been found to estimate reliable mortality rates at the national level (A. Gupta \& Sudharsanan, 2020). In addition to the household death question, NFHS-5 asked about the proportion of these deaths that were "registered with the civil authority." This proportion was 97.4 percent (Government of India, 2020).

${ }^{3}$ SRS crude death rates rates are collated from SRS annual reports and compendiums. CRS rates are collated from annual reports of the CRS (Office of the Registrar General and Census Commissioner of India, 2013) and reports published by the Department of Economics and Statistics, Government of Kerala (Government of Kerala, 2009). The CRS rates use official projections from the Indian census for population exposures. It is possible that a part of the difference between the CRS and SRS is due to differences in underlying population exposures. Unfortunately, the population estimates and survey weights which the SRS uses for calculation of crude and age-specific mortality rates are not available in the public domain, and thus direct comparison using the same population estimates cannot be made.

${ }^{4}$ We note that this study identifies the early 2000s as an important period in which mortality registration improved dramatically, but causes for this improvement are not exactly clear. The computerization of vital 
registration in Kerala in this period certainly would have helped. It is possible that earlier estimates of crude death rates from the CRS are underestimates because some death certificates were issued as paper certificates by local officials but were not recorded in centralized databases that were reported to the Office of the Registrar General and Census Commissioner of India. Computerization of registration would reduce the extent to which these paper death certificates are missed. An additional factor could be state initiatives. According to the 2009 all-India CRS Report, Kerala was one of only three states that had modest fines for delayed and non-registration of deaths (Office of the Registrar General and Census Commissioner of India, 2013). Other initiatives, such as information campaigns and audits of registration authorities in Kerala, are discussed in multiple CRS reports. However, further qualitative research and interviews would be useful in understanding the relative contribution of these and other factors in improving the CRS in Kerala.

${ }^{5}$ Another source of difference can be how the different sources treat deaths of migrants. We examine the extent to which migration may affect CRS rates in the Supplementary Appendix. Our analysis suggests that excluding migrants from the CRS does not change overall crude deaths rate substantially. The SRS estimates mortality rates for usual residents, but the definition of a usual resident is not available from the SRS reports.

${ }^{6}$ Information on the extent to which older sampling units were discarded in these revisions is not available. For the revision in the 1980s, Bhat et al. (1984) note that "about 58 per cent of the old sample units based on the 1961 census were replaced by new sample units drawn from the 1981 census frame" (p.39).

${ }^{7}$ We borrow sex-specific ${ }_{n} a_{x}$ values from the SRS abridged life tables for Kerala. The ${ }_{n} a_{x}$ estimates for 2006 come from the 2004-2008 SRS abridged life tables, for 2007 from the 2005-2009 SRS abridged life tables, and so on. We do not redistribute the deaths with missing age or sex information, nor do we use any smoothing techniques. We also calculate the probability of death for the ages 0-15, 15-60, and 60-85.

\footnotetext{
${ }^{8}$ We do not redistribute the deaths that have missing information on age or sex. We drop these observations.
}

${ }^{9}$ This deterioration in the SRS to capture mortality could be because of changes in the SRS panel, or because of difficulty in capturing deaths as mortality declines. If underlying individual level SRS data are available, this could be examined in detail. Appendix Figure A1 reports ratios of mortality rates between the CRS and the SRS by age.

${ }^{10}$ The NFHS is India's version of the Demographic Health Surveys (DHS). We calculate age-specific mortality by year in the NFHS by using the approach outlined in Moultrie et al. (2013) and Gupta (2020b). In particular, we estimated person years lived and deaths in the age group $0-1$ for the individual years for 2004 to 2015.

${ }^{11}$ The SRS also does not provide estimates of sex-specific infant mortality rates in its annual reports. In Appendix Figure A4 we compare estimates for infant mortality rates from the SRS with those from the CRS (calculated by dividing infant deaths and births in a year). This figure also confirms that patterns observed in Appendix Figure A2 are not due to biases in the estimation of the $0-1$ population.

${ }^{12}$ The UN Demographic Yearbook 2018 calculates the Whipple index for the Indian census of 1991, 2001, and 2011. The Whipple index for the Indian census population has improved over the decades from 290.3 in 1991, to 230 in 2001, to 171 in 2011.

${ }^{13}$ Given the additional similarity in mortality rates when using Census 2011 population and adjusted population estimates from the DHS Program (2020), as reported in the "Alternative population exposures" section, it is reasonable to argue that mortality rates and life tables reported for other years will not substantially change if single-year population exposures were available for those years and Gompertz mortality rates were calculated instead of unadjusted mortality rates.

${ }^{14}$ Reports from the vital statistics system (Government of Kerala, 2019) do report crude death rates, the infant mortality rate (calculated by dividing infant deaths and births), and other indicators, such as the sex ratio at birth.

${ }^{15}$ At the time of writing, April 2021, the last available reports are for 2018. 


\section{References}

AbouZahr, C., De Savigny, D., Mikkelsen, L., Setel, P. W., Lozano, R., \& Lopez, A. D. (2015). Towards universal civil registration and vital statistics systems: The time is now. The Lancet, 386(10001), 1407-1418. https:// doi.org/10.1016/S0140-6736(15) 60170-2

AbouZahr, C., Rampatige, R., Lopez, A., \& de Savigny, D. (2012). When civil registration is inadequate: interim methods for generating vital statistics. Pacific Health Dialog, 18(1), 215-30. https: / / www.researchgate.net/publication/233928902_When _civil_registration_is_inadequate_interim_methods_for_generating_vital_statistics

Alkema, L., Chao, F., You, D., Pedersen, J., \& Sawyer, C. C. (2014). National, regional, and global sex ratios of infant, child, and under-5 mortality and identification of countries with outlying ratios: a systematic assessment. The Lancet Global Health, 2(9), e521-e530. https: / / doi.org/10.1016/S2214-109X(14)70280-3

Amouzou, A., Kante, A., Macicame, I., Antonio, A., Gudo, E., Duce, P., \& Black, R. E. (2020). National sample vital registration system: A sustainable platform for covid19 and other infectious diseases surveillance in low and middle-income countries. Journal of global health, 10(2). http: / / dx.doi.org/10.7189/jogh.10.020368

Balabanova, D., Mills, A., Conteh, L., Akkazieva, B., Banteyerga, H., Dash, U., ... McKee, M. (2013). Good health at low cost 25 years on: lessons for the future of health systems strengthening. The Lancet, 381(9883), 2118-2133. https:/ / doi.org/10.1016/ S0140-6736(12)62000-5

Banaji, M., \& Gupta, A. (2021). Estimates of pandemic excess mortality in india based on civil registration data. medRxiv.

Barbieri, M., Wilmoth, J. R., Shkolnikov, V. M., Glei, D., Jasilionis, D., Jdanov, D., ... Winant, C. (2015). Data resource profile: the Human Mortality Database (HMD). International journal of epidemiology, 44(5), 1549-1556. https:/ / doi.org/10.1093/ije/ dyv105

Bhagat, R. B., \& Keshri, K. (2020). Internal migration in India. In Internal migration in the countries of asia (pp. 207-228). Springer. http:/ / dx.doi.org/10.1007/978-3-030-44010 $-7 \_11$

Bhat, P. M. (2002). Completeness of India's sample registration system: an assessment using the general growth balance method. Population studies, 56(2), 119-134. https:/ / www.jstor.org/stable/25764243

Bhat, P. M., Preston, S. H., \& Dyson, T. (1984). Vital rates in India, 1961-1981 (Vol. 24). National Academies.

Bhatia, A., Krieger, N., Beckfield, J., Barros, A. J., \& Victora, C. (2019). Are inequities decreasing? Birth registration for children under five in low-income and middleincome countries, 1999-2016. BMJ global health, 4(6). https://doi.org/10.1136/ bmjgh-2019-001926

Bhatia, A., Victora, C. G., Beckfield, J., Budukh, A., \& Krieger, N. (2021). "registries are not only a tool for data collection, they are for action": Cancer registration and gaps in data for health equity in six population-based registries in india. International Journal of Cancer, 148(9), 2171-2183. https://doi.org/10.1002/ijc.33391 
Brass, W. (1975). Methods for estimating fertility and mortality from limited and defective data..

Brown, D. C., Lariscy, J. T., \& Kalousová, L. (2019). Comparability of mortality estimates from social surveys and vital statistics data in the united states. Population Research and Policy Review, 38(3), 371-401. https://link.springer.com/article/10.1007/s11113 -018-9505-1

Caldwell, J. C. (1986). Routes to low mortality in poor countries. Population and Development Review, 171-220. https: / / doi.org/10.2307/1973108

Clark, S. J. (2019). A general age-specific mortality model with an example indexed by child mortality or both child and adult mortality. Demography, 56(3), 1131-1159. https:/ / doi.org/10.1007/s13524-019-00785-3

Department of International Economic and Social Affairs. (1983). Manual X. Indirect Techniques for Demographic Estimation. United Nations Publications. Retrieved 2020-1107, from https://www.un.org/en/development/desa/population/publications/ manual/estimate/demographic-estimation.asp.

DHS Program. (2020). Spatial Data Repository - Population Estimates. Retrieved 2020-12-25, from https:/ / spatialdata.dhsprogram.com/population-estimates /

Dreze, J., Gupta, A., Parashar, S. A., \& Sharma, K. (2020). Pauses and reversals of infant mortality decline in India in 2017 and 2018. http: / / dx.doi.org/10.2139/ssrn.372700

Feehan, D. M., \& Borges, G. M. (2019). Estimating adult death rates from sibling histories: A network approach. arXiv preprint arXiv:1906.12000. https://doi.org/10.1215/ 00703370-9368990

Feehan, D. M., Mahy, M., \& Salganik, M. J. (2017). The network survival method for estimating adult mortality: Evidence from a survey experiment in rwanda. Demography, 54(4), 1503-1528. https:/ / doi.org/10.1007/s13524-017-0594-y

Garenne, M., Collinson, M. A., Kabudula, C. W., Gómez-Olivé, F. X., Kahn, K., \& Tollman, S. (2016). Completeness of birth and death registration in a rural area of south africa: the agincourt health and demographic surveillance, 1992-2014. Global health action, 9(1), 32795. https:/ / doi.org/10.3402/gha.v9.32795

Gerland, P. (2014). UN Population Division's methodology in preparing base population for projections: case study for India. Asian Population Studies, 10(3), 274-303. http: / / dx.doi.org/10.1080/17441730.2014.947059

Glei, D., Paz, A. B., Aburto, J. M., \& Barbieri, M. (2021). Mexican mortality 1990-2016: Comparison of unadjusted and adjusted estimates. Demographic Research, 44, 719758. https://dx.doi.org/10.4054/DemRes.2021.44.30

Glei, D. A., Barbieri, M., \& Santamaría-Ulloa, C. (2019). Costa Rican mortality 1950-2013: An evaluation of data quality and trends compared with other countries. Demographic research, 40, 835. https:/ / doi.org/10.4054/demres.2019.40.29

Government of India. (2011). Census of India 2011: House listing Operations. Housing and Houselisting Operations.

Government of India. (2020). Fact Sheets: Key Indicators - 22 States/UTs from Phase 1; National Family Health Survey (NFHS-5) 2019-20 (Report). International Institute for Population Sciences and Ministry of Health and Family Welfare. http:// rchiips.org/nfhs/factsheet_NFHS-5.shtml 
Government of Kerala. (2008). Annual report for the year 2007-2008. Information Kerala Mission, Department of Local Self Goverment. https://ikm.gov.in/sites/default/files/ annualreport_\%202007-2008.pdf

Government of Kerala. (2009). Vital Statistics - A Trend Analysis. Department of Economics and Statistics.

Government of Kerala. (2019). Annual vital statistics report 2018. Department of Economics and Statistics. Retrieved 2021-03-01, from http:/ / www.ecostat.kerala.gov.in/ images/pdf/publications/Vital_Statistics/data/vital_statistics_2018.pdf

Government of Kerala. (2020). Annual report for the year 2018-2019. Information Kerala Mission, Department of Local Self Goverment. https://ikm.gov.in/en/article/annual -report-2018-2019

Government of Kerala. (2021). Reduction in all-cause mortality in Kerala during Covid-19 pandemic (Technical Report). Department of Health and Family Welfare. Retrieved 202106-03, from https://health.kerala.gov.in/pdf/Technica_paper_All_Cause_Mortality Kerala_March 21.pdf

Gupta, A. (2020). COVID-19 and the importance of improving civil registration in India. (Tech. Rep.). Center for Advanced Study of India. University of Pennsylvania. Retrieved 2020-7-13, from https://casi.sas.upenn.edu/iit/aashishgupta

Gupta, A., Rukmini, S., \& Rajendran, D. (2021). India's covid death reporting is broken but here's how to fix it. TheWire.in. Retrieved 2021-06-12, from https://thewire.in/ health/india-covid-19-death-reporting

Gupta, A., \& Sudharsanan, N. (2020). Large and persistent life expectancy disparities among india's social groups. https:// doi.org/10.31235/osf.io\%2Fhu8t9

Gupta, M., Rao, C., Lakshmi, P., Prinja, S., \& Kumar, R. (2016). Estimating mortality using data from civil registration: a cross-sectional study in india. Bulletin of the World Health Organization, 94(1), 10. https:/ /dx.doi.org/10.2471\%2FBLT.15.153585

Heller, P. (2006). Kerala: Deepening a radical social democracy. Social Democracy in the Global Periphery: Origins, Challenges, and Prospects, 65-92.

Hill, K. (1991). Approaches to the measurement of childhood mortality: a comparative review. Population Index, 368-382. https://doi.org/10.2307/3643873

Hill, K., et al. (2017). Analytical methods to evaluate the completeness and quality of death registration: current state of knowledge. Population Division Technical Paper(2017/02). https://www.un.org/en/development/desa/population/ publications/pdf/technical/TP2017-2.pdf.

Hill, K., You, D., \& Choi, Y. (2009). Death distribution methods for estimating adult mortality: sensitivity analysis with simulated data errors. Demographic Research, 21, 235-254. http:/ / dx.doi.org/10.1080/00324728.2020.1854332

James, K., Kulkarni, P., Sathyanarayana, K., Kumar, S., George, A., \& Prasad, S. (2013). A preliminary assessment of the quality of civil registration system in Kerala, Odisha and Rajasthan, United Nations Population Fund (Report). UNFPA, JNU, and ISEC.

Kuhn, R. (2010). Routes to low mortality in poor countries revisited. Population and Development Review, 36(4), 655-692. https:/ / doi.org/10.1111/j.1728-4457.2010.00353 . $\mathrm{X}$

Kumar, A. J. (2021). TOI exclusive: Over 6,000 certified covid deaths miss- 
ing from Kerala's official toll. The Times of India. Retrieved 2021-0715, from https://timesofindia.indiatimes.com/city/thiruvananthapuram/ over-6000-certified-covid-deaths-missing-from-keralas-official-toll/articleshow / 84256643.cms

Kumar, G. A., Dandona, L., \& Dandona, R. (2019). Completeness of death registration in the Civil Registration System, India (2005 to 2015). The Indian Journal of Medical Research, 149(6), 740. http:/ /dx.doi.org/10.4103/ijmr.IJMR_1620_17

Leddy Jr, R. M. (2016). Methods for calculating 5-Year age group population estimates by sex for subnational areas: Version 2. Population Division. Geographic Studies Branch, US Census Bureau. Retrieved 2020-1107, from https://www2.census.gov/programs-surveys/international-programs/ about/global-mapping/subntl-pop-est-methods-pgs-uscb-dec16.pdf.

Liu, S., Wu, X., Lopez, A. D., Wang, L., Cai, Y., Page, A., . . others (2016). An integrated national mortality surveillance system for death registration and mortality surveillance, china. Bulletin of the World Health Organization, 94(1), 46. https:/ /dx.doi.org/ 10.2471\%2FBLT.15.153148

Mahapatra, P. (2017). The Sample Registration System (SRS) in India, an overview, as of 2017 (Working paper). Prince Mahidol Award Conference and Global Health Information Forum.

Masquelier, B. (2013). Adult mortality from sibling survival data: a reappraisal of selection biases. Demography, 50(1), 207-228. http://dx.doi.org/10.1007/s13524-012 $-0149-1$

Masquelier, B., Kanyangarara, M., Pison, G., Kanté, A. M., Ndiaye, C. T., Douillot, L., ... Helleringer, S. (2020). Errors in reported ages and dates in surveys of adult mortality: A record linkage study in Niakhar (Senegal). Population Studies, 1-19.

Mathers, C. D., Ma Fat, D., Inoue, M., Rao, C., \& Lopez, A. D. (2005). Counting the dead and what they died from: an assessment of the global status of cause of death data. Bulletin of the World Health Organization, 83, 171-177c. http://www.ncbi.nlm .nih.gov/pmc/articles/pmc2624200

Moultrie, T. A., Dorrington, R., Hill, A. G., Hill, K., Timæus, I., \& Zaba, B. (2013). Tools for demographic estimation. International Union for the Scientific Study of Population.

Murray, C. J., Ferguson, B. D., Lopez, A. D., Guillot, M., Salomon, J. A., \& Ahmad, O. (2003). Modified logit life table system: principles, empirical validation, and application. Population studies, 57(2), 165-182. https://www.jstor.org/stable/3595746

National Commission on Population. (2019). Report of the technical group on population projections: Population Projections for India and States, 2011-2036. New Delhi: Ministry of Health and Family Welfare.

Office of the Registrar General and Census Commissioner of India. (2011). Census of India 2011: Household listing Operations. Office of the Registrar General Census Commissioner, India. Indian Census Bureau.

Office of the Registrar General and Census Commissioner of India. (2013). Vital statistics of India based on the civil registration system 2009 (Tech. Rep.). Office of the Registrar General and Census Commissioner, Government of India. Retrieved 2021-1-14, from https:/ / crsorgi.gov.in/web/uploads/download/CRS_Report_2009.pdf 
Office of the Registrar General and Census Commissioner of India. (2018). Abridged life tables based on the sample registration system, 2012-2016 (Tech. Rep.). Government of India. Retrieved 2020-12-23, from https:/ / www.censusindia.gov.in/Vital_Statistics/ SRS_Life_Table/SRS-12-16/2.Analysis_2012-16.pdf

ORGI. (2016). India Sample Registration System Baseline Survey 2014 (report). Office of the Registrar General and Census Commissioner of India, Ministry of Home Affairs, Government of India New Delhi.

ORGI. (2020). Vital Statistics of India Based on the Civil Registration System 2018 (Tech. Rep.). Office of the Registrar General and Census Commissioner, Government of India.

Preston, S., Elo, I. T., \& Stewart, Q. (1999). Effects of age misreporting on mortality estimates at older ages. Population studies, 53(2), 165-177. https:/ /www.jstor.org/ stable/2584674

Preston, S., Heuveline, P., \& Guillot, M. (2001). Demography: measuring and modeling population processes. MA: Blackwell Publishing. http://dx.doi.org/10.2307/ 1535065

Rajan, S. I., \& Mohanachandran, P. (1999). Estimating infant mortality in Kerala. Economic and Political Weekly, 713-716. https://www.jstor.org/stable/4407764

Rajan, S. I., \& Zachariah, K. C. (2019). Emigration and remittances: New evidences from the Kerala migration survey 2018 (Tech. Rep.).

Rajendran, D., \& Kurian, S. (2021). TNM exclusive: Kerala reports excess deaths till end of may 2021. The News Minute. Retrieved 2021-0715, from https://www.thenewsminute.com/article/tnm-exclusive-kerala-reports -almost-14000-excess-deaths-till-end-may-2021-151124

Ramachandran, V. (1997). On Kerala's development achievements," in J. Dreze and A. Sen, Indian development: Selected regional perspectives, Oxford University Press, London.

Ramaiah, A. (2015). Health status of dalits in india. Economic and Political Weekly, 50(43), 70-74. https://www.epw.in/journal/2015/43/notes/health-status-dalits -india.html

Ramani, S. (2021). 'excess deaths' in Kerala 1.6 times official covid-19 toll. The Hindu. Retrieved 2021-07-15, from https: / /www.thehindu.com/news/national/ excess-deaths-in-kerala-16-times-official-covid-19-toll/article34978628.ece

Rao, C., Gupta, A., Gupta, M., \& Yadav, A. K. (2021). Premature adult mortality in india: what is the size of the matter? BMJ Global Health, 6(6), e004451. https://doi.org/ 10.1136/bmjgh-2020-004451

Rao, C., \& Gupta, M. (2020). The civil registration system is a potentially viable data source for reliable subnational mortality measurement in India. BMJ Global Health, 5(8), e002586. https://doi.org/10.1136/bmjgh-2020-002586

RGI. (2016). Compendium of India's Fertility and Mortality Indicators 1971-2013 based on the Sample Registration System (SRS). Office of the Registrar Genegral and Census Commissioner of India, New Delhi, Government of India.

Saikia, N., Bora, J. K., \& Luy, M. (2019). Socioeconomic disparity in adult mortality in India: estimations using the orphanhood method. Genus, 75(1), 7. https:/ / doi.org/ 10.1016/S2214-109X(14)70280-3 
Saikia, N., Singh, A., \& Ram, F. (2010). Has child mortality in India really increased in the last two decades? Economic and Political Weekly, 62-70. https://www.jstor.org/ stable/25764243

Sawyer, C. C. (2012). Child mortality estimation: estimating sex differences in childhood mortality since the 1970s. PLoS Med, 9(8), e1001287. https://doi.org/10.1371/ journal.pmed.1001287

Sen, A. (2001). Development as freedom. Oxford Paperbacks.

Setel, P. W., Sankoh, O., Rao, C., Velkoff, V. A., Mathers, C., Gonghuan, Y., ... Lopez, A. D. (2005). Sample registration of vital events with verbal autopsy: a renewed commitment to measuring and monitoring vital statistics. Bulletin of the World Health Organization, 83, 611-617. http://www.ncbi.nlm.nih.gov/pmc/articles/pmc2626308/

Szreter, S., \& Breckenridge, K. (2012). Recognition and registration: The infrastructure of personhood in world history. In Proceedings of the British academy (Vol. 182, pp. 1-36). 10.5871/bacad/9780197265314.001.0001

Timaeus, I. M. (1991). Measurement of adult mortality in less developed countries: a comparative review. Population index, 552-568. http:/ /dx.doi.org/10.2307/3644262

Timæus, I. M., \& Jasseh, M. (2004). Adult mortality in sub-saharan africa: evidence from demographic and health surveys. Demography, 41(4), 757-772. https://www.jstor .org/stable/1515229

United Nations. (2019a). United Nations demographic yearbook 2018. UN. Retrieved 202101-05, from https://www.un-ilibrary.org/content/books/9789210043663/read.

United Nations. (2019b). World population prospects 2019, volume ii: Demographic profiles: India (Report). Department of Economic and Social Affairs, Population Division. Retrieved 2021-01-15, from https://population.un.org/wpp/Publications/ Files/WPP2019_Volume-II-Demographic-Profiles.pdf.

US Department of Health and Human Services and others. (2020). Protection of human subjects. 45 CFR § 46. Subpart A.

Varghese, J. S., Gupta, A., Mehta, R., Stein, A. D., \& Patel, S. A. (2021). Changes in child undernutrition and overweight in india from 2006 to 2019: An analysis of 22 states. http:/ /dx.doi.org/10.21203/rs.3.rs-537129/v1

Vyas, S., \& Hathi, A., Payal andd Gupta. (2021). Social disadvantage, economic inequality, and life expectancy in nine indian states. http://dx.doi.org/10.31235/osf.io/vkacx

Wilmoth, J., Zureick, S., Canudas-Romo, V., Inoue, M., \& Sawyer, C. (2012). A flexible two-dimensional mortality model for use in indirect estimation. Population studies, 66(1), 1-28. https:/ /www.jstor.org/stable/41721283 
Table 1 Descriptive statistics: Observed deaths, estimated crude death rates, and deaths with missing age or sex

\begin{tabular}{|c|c|c|c|c|c|c|c|c|}
\hline \multirow{2}{*}{ Year } & \multicolumn{2}{|c|}{ Female } & \multicolumn{2}{|c|}{ Male } & \multicolumn{2}{|c|}{ Total } & \multicolumn{2}{|c|}{ Missing } \\
\hline & Deaths & CDR & Deaths & CDR & Deaths & CDR & $\mathrm{N}$ & Percent \\
\hline 2006 & 88,131 & 5.3 & 125,103 & 8.0 & 213,234 & 6.6 & 4,333 & 2.0 \\
\hline 2007 & 97,784 & 5.8 & 136,981 & 8.8 & 234,765 & 7.3 & 3,972 & 1.7 \\
\hline 2008 & 91,789 & 5.5 & 126,037 & 8.0 & 217,826 & 6.7 & 2,493 & 1.1 \\
\hline 2009 & 97,334 & 5.8 & 132,282 & 8.4 & 229,616 & 7.1 & 2,272 & 1.0 \\
\hline 2010 & 101,122 & 6.0 & 136,057 & 8.7 & 237,179 & 7.3 & 2,178 & 0.9 \\
\hline 2011 & 100,867 & 6.0 & 135,283 & 8.6 & 236,150 & 7.2 & 1,594 & 0.7 \\
\hline 2012 & 108,298 & 6.4 & 127,729 & 8.1 & 236,027 & 7.2 & 1,305 & 0.5 \\
\hline 2013 & 110,375 & 6.5 & 143,867 & 9.1 & 254,242 & 7.8 & 1,222 & 0.5 \\
\hline 2014 & 105,154 & 6.2 & 136,376 & 8.6 & 241,530 & 7.4 & 1,016 & 0.4 \\
\hline 2015 & 107,509 & 6.3 & 136,006 & 8.6 & 243,515 & 7.4 & 1,166 & 0.5 \\
\hline 2016 & 111,269 & 6.5 & 138,395 & 8.8 & 249,664 & 7.6 & 1,166 & 0.5 \\
\hline 2017 & 107,593 & 6.3 & 135,461 & 8.6 & 243,054 & 7.4 & 780 & 0.3 \\
\hline
\end{tabular}

Note: Calculated from civil registration Data in the Kerala MARANAM Study and population exposures from the DHS Program (2020). CDR is the crude death rate per 1,000. Deaths and CDR exclude observations with missing age or sex information. These observations are shown as missing. Four observations were dropped due to missing year. 
Table 2 Probability of dying between ages $0-15,15-60$, and $60-85$; by year and sex

\begin{tabular}{|c|c|c|c|c|c|c|}
\hline \multirow{3}{*}{ Year } & \multicolumn{6}{|c|}{ Probability of dying } \\
\hline & \multicolumn{2}{|c|}{ ages $0-15$} & \multicolumn{2}{|c|}{ ages $15-60$} & \multicolumn{2}{|c|}{ ages $60-85$} \\
\hline & Female & Male & Female & Male & Female & Male \\
\hline 2006 & 0.0132 & 0.0158 & 0.0685 & 0.1679 & 0.5659 & 0.7508 \\
\hline 2007 & 0.0134 & 0.0169 & 0.0750 & 0.1825 & 0.6172 & 0.8022 \\
\hline 2008 & 0.0114 & 0.0147 & 0.0716 & 0.1723 & 0.5879 & 0.7684 \\
\hline 2009 & 0.0107 & 0.0132 & 0.0718 & 0.1755 & 0.5941 & 0.7726 \\
\hline 2010 & 0.0097 & 0.0121 & 0.0723 & 0.1808 & 0.5893 & 0.7584 \\
\hline 2011 & 0.0098 & 0.0120 & 0.0703 & 0.1794 & 0.6103 & 0.7798 \\
\hline 2012 & 0.0114 & 0.0119 & 0.0851 & 0.1575 & 0.6110 & 0.7566 \\
\hline 2013 & 0.0096 & 0.0115 & 0.0697 & 0.1783 & 0.6200 & 0.7880 \\
\hline 2014 & 0.0086 & 0.0107 & 0.0665 & 0.1688 & 0.6083 & 0.7732 \\
\hline 2015 & 0.0082 & 0.0099 & 0.0695 & 0.1636 & 0.6174 & 0.7714 \\
\hline 2016 & 0.0077 & 0.0094 & 0.0658 & 0.1582 & 0.6243 & 0.7788 \\
\hline 2017 & 0.0089 & 0.0103 & 0.0682 & 0.1580 & 0.6307 & 0.7891 \\
\hline
\end{tabular}

Note: Authors' calculations using data from the Kerala MARANAM Study and adjusted population estimates from the DHS Program (2020). 
Table 3 Estimates for life expectancy at birth, age 15, age 60; by year and sex

\begin{tabular}{|c|c|c|c|c|c|c|}
\hline \multirow{3}{*}{ Year } & \multicolumn{6}{|c|}{ Life expectancy at } \\
\hline & \multicolumn{2}{|c|}{ birth } & \multicolumn{2}{|c|}{ age 15} & \multicolumn{2}{|c|}{ age 60} \\
\hline & Female & Male & Female & Male & Female & Male \\
\hline 2011 & 78.2 & 70.9 & 64.0 & 56.7 & 21.4 & 17.0 \\
\hline 2012 & 77.5 & 72.3 & 63.3 & 58.1 & 21.2 & 17.9 \\
\hline 2013 & 78.0 & 70.8 & 63.8 & 56.6 & 21.1 & 16.9 \\
\hline 2014 & 78.4 & 71.4 & 64.1 & 57.1 & 21.3 & 17.1 \\
\hline 2015 & 78.2 & 71.6 & 63.8 & 57.3 & 21.1 & 17.2 \\
\hline 2016 & 78.2 & 71.7 & 63.8 & 57.4 & 20.9 & 17.1 \\
\hline 2017 & 77.9 & 71.4 & 63.6 & 57.2 & 20.8 & 16.8 \\
\hline
\end{tabular}

Note: Authors' calculations using data from the Kerala MARANAM Study and adjusted population estimates from the DHS Program (2020). 
Figure 1 Estimated crude death rates, Kerala, 1971-2017

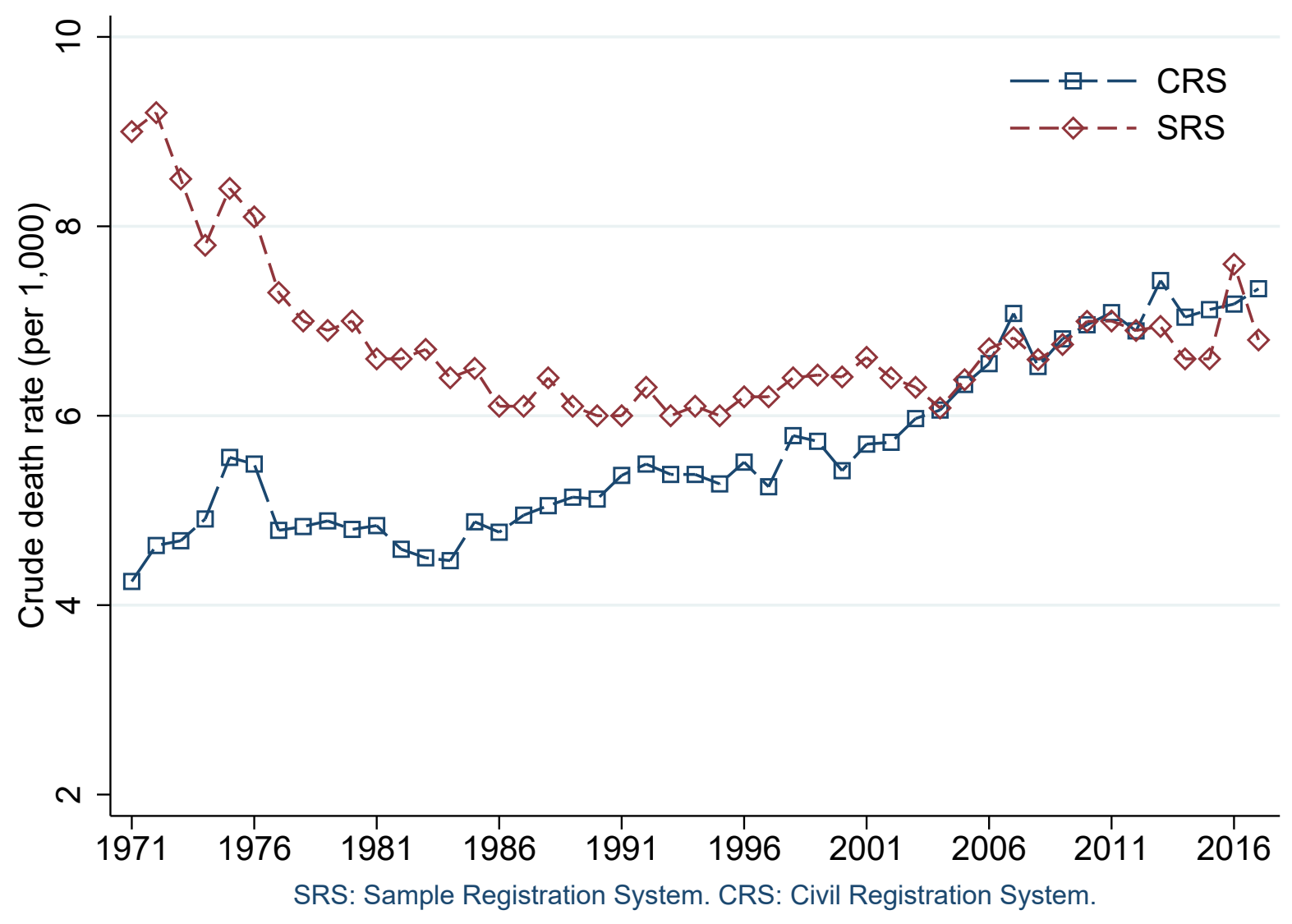


Figure 2 Comparison of age-specific mortality rates $\left({ }_{n} m_{x}\right)$, female, 2006-2017
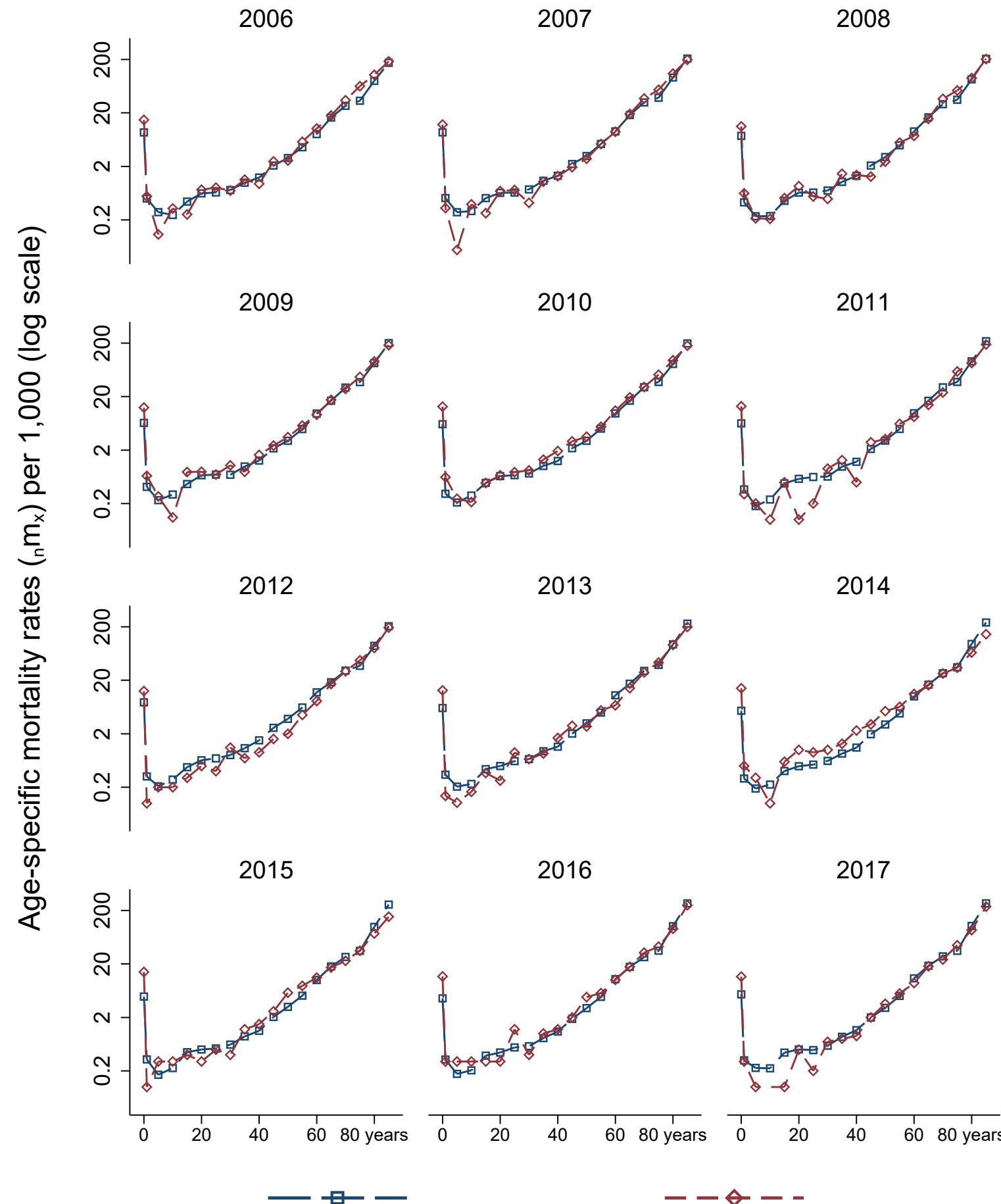
Figure 3 Comparison of age-specific mortality rates $\left({ }_{n} m_{x}\right)$, male, 2006-2017
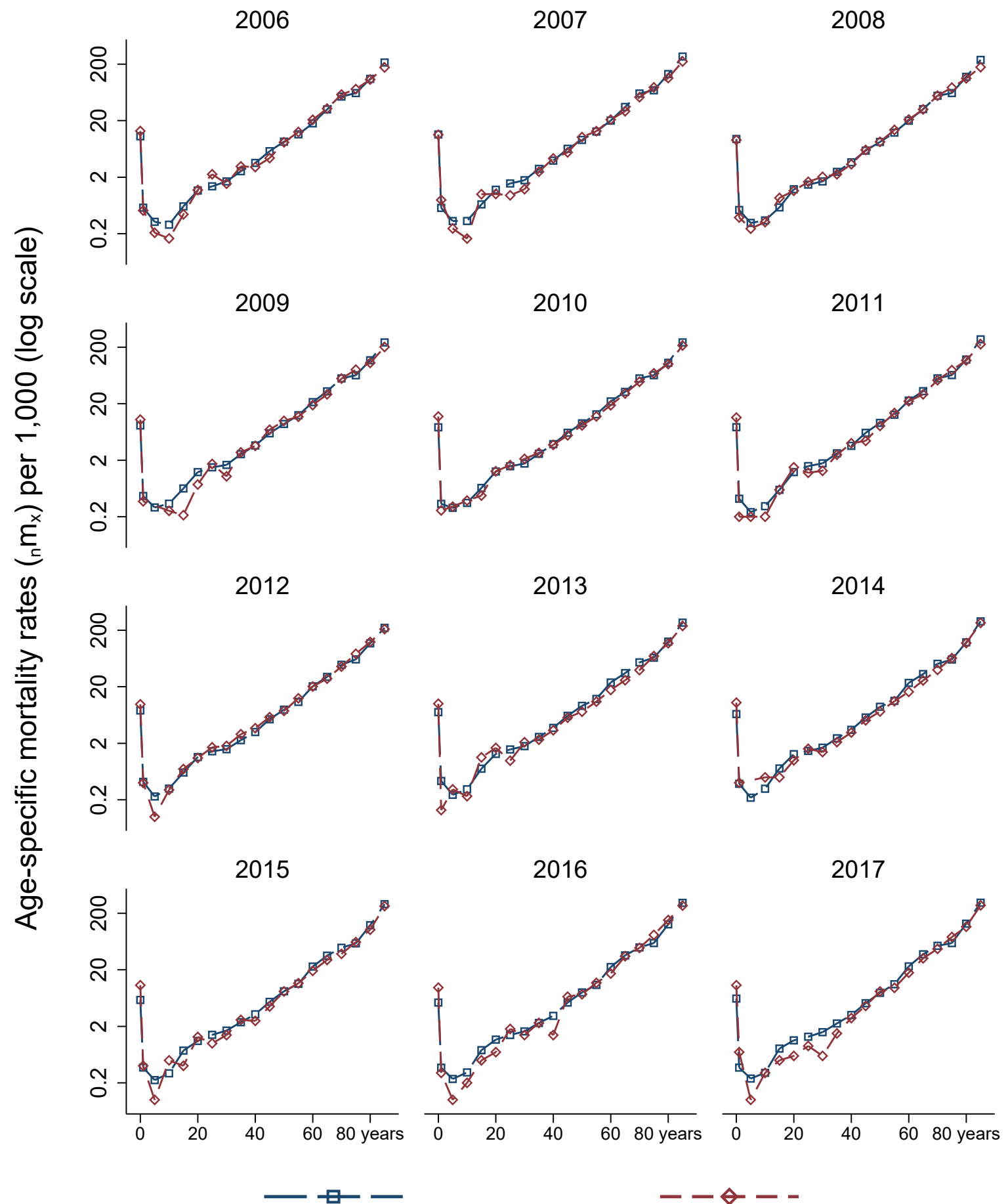

Civil Registration System (CRS)

Sample Registration System (SRS)

CRS estimates are authors' calculations using data from the Kerala MARANAM Study and adjusted population estimates from the DHS Program (2020). SRS estimates are from SRS annual reports. 


\section{SUPPLEMENTARY APPENDIX}

\section{Migration and mortality estimates}

Kerala is a high-migration context. In 2011, the Kerala Migration Survey estimated that 2.28 million emigrants from Kerala lived across the world (Rajan \& Zachariah, 2019). ${ }^{16}$ It is not clear the extent to which the deaths of migrants from Kerala are missed by the Civil Registration System (CRS) and the degree to which these deaths bias mortality estimates reported here. These deaths should be included if the people dying were usual residents of Kerala. Similarly, the population estimates in the denominator of our mortality calculations are also for usual residents of Kerala. ${ }^{17}$

\section{International migration}

Based on data we have access to, we do not know the exact number of people who died outside India but were usual residents of Kerala to include them in our mortality estimates. The closest estimate available is the overall death counts provided by Indian embassies for 2009 to 2016. In 2009, 1,222 deaths were registered at all Indian consulates and missions abroad. This number was 1,652 deaths in 2010, 1,745 deaths in 2011, 1,754 deaths in 2012, 1,106 deaths in 2013, 4,161 deaths in 2014, 4,160 deaths in 2015, and 4,266 deaths in 2016. These total deaths are a small fraction of overall deaths in the CRS. Indeed, the highest number of deaths was in 2016, and these deaths are just 1.7 percent of the total deaths registered in that year. Although it would be useful to understand mortality patterns among migrants from Kerala, it is likely that additional information on these deaths will not alter the estimated mortality rates and life expectancy values.

\section{Internal migration}

Kerala is ranked above other Indian states in its performance on migrant-friendly policies and attracts migrant labor from other parts of India (Bhagat \& Keshri, 2020). In 2011, the Indian census counted about 683,828 individuals who were living in Kerala but were born outside the state (Office of the Registrar General and Census Commissioner of India, 2011). The census also counted 654,423 individuals whose last residence was outside Kerala but within another state of India. Of these, about 80,045 individuals' last place of residence was outside the state of Kerala in the last year. In Appendix Table A9, we examine changes in the crude death rate for Kerala if these individuals are removed from the denominator. We also examine the extent to which the crude death rate changes if we exclude those deaths for persons whose state of permanent residence was not Kerala according to the CRS. In general, Appendix Table A9 shows that excluding those with permanent residence reported to be outside Kerala, people born outside Kerala, or people whose last residence was outside Kerala in the last year does not change the estimated crude death rate substantially. It is worth noting that some of the people excluded here may in fact be usual residents. If true estimates of usual residents among those who are alive or dead are available, changes in the crude death rates will likely be smaller than the ones reported here. 
Figure A1 Ratio of mortality rates from the civil and sample registration systems

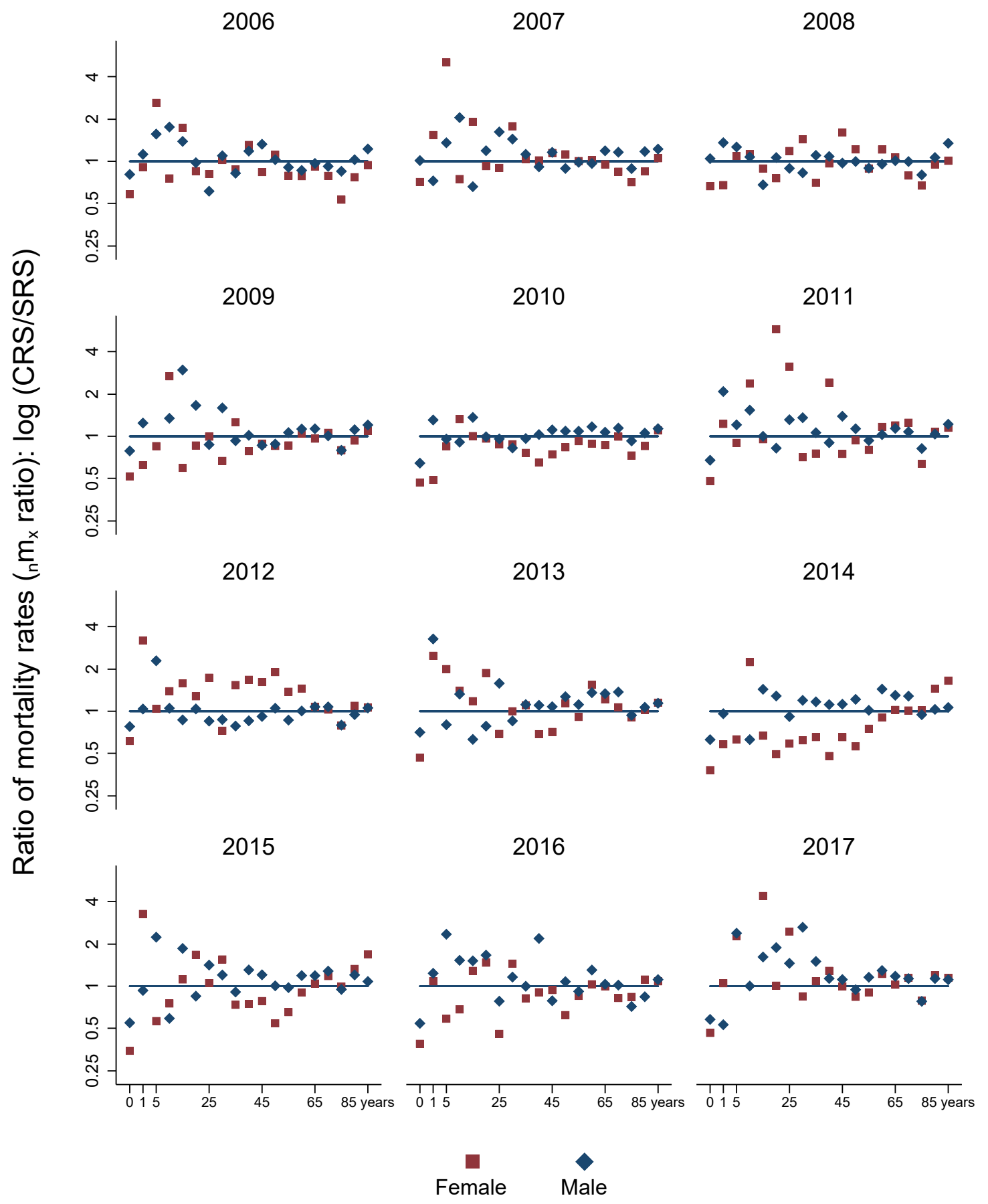

Sample Registration System (SRS) estimates are from SRS annual reports. Civil Registration System (CRS) estimates are calculated from observed CRS deaths and estimated mid-year population. 
Figure A2 Comparison of estimates of ${ }_{1} \mathrm{~m}_{0}$

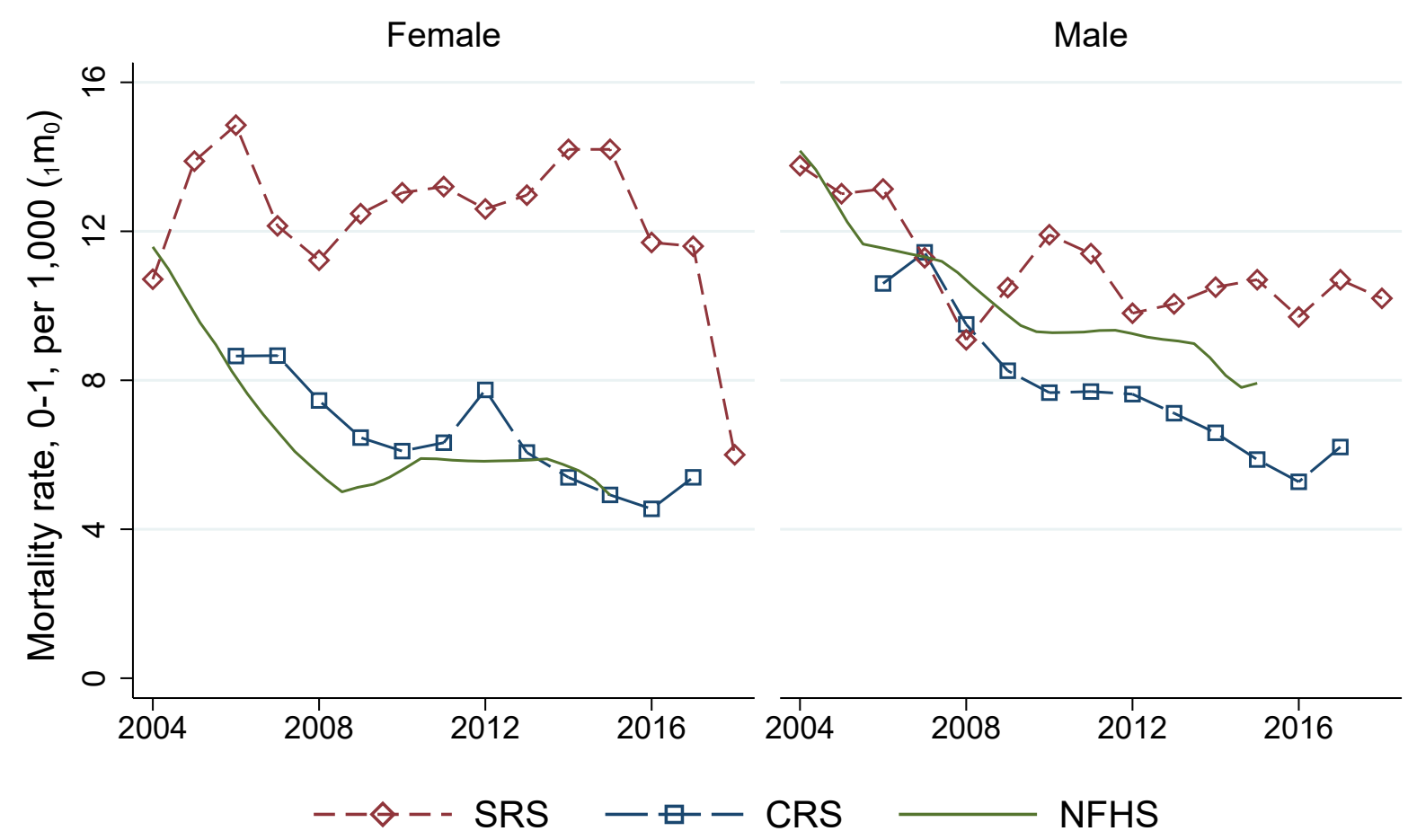

National Family Health Survey (NFHS) estimates are smoothed and reflect two-year moving averages. NFHS estimates are calculated by estimating person years lived and deaths in each year. Sample Registration System (SRS) estimates are from SRS annual reports. Civil Registration System (CRS) estimates are calculated from observed CRS deaths and estimated mid-year population. 
Figure A3 Comparison of sex ratios of ${ }_{1} \mathrm{~m}_{0}$ (boys v girls)

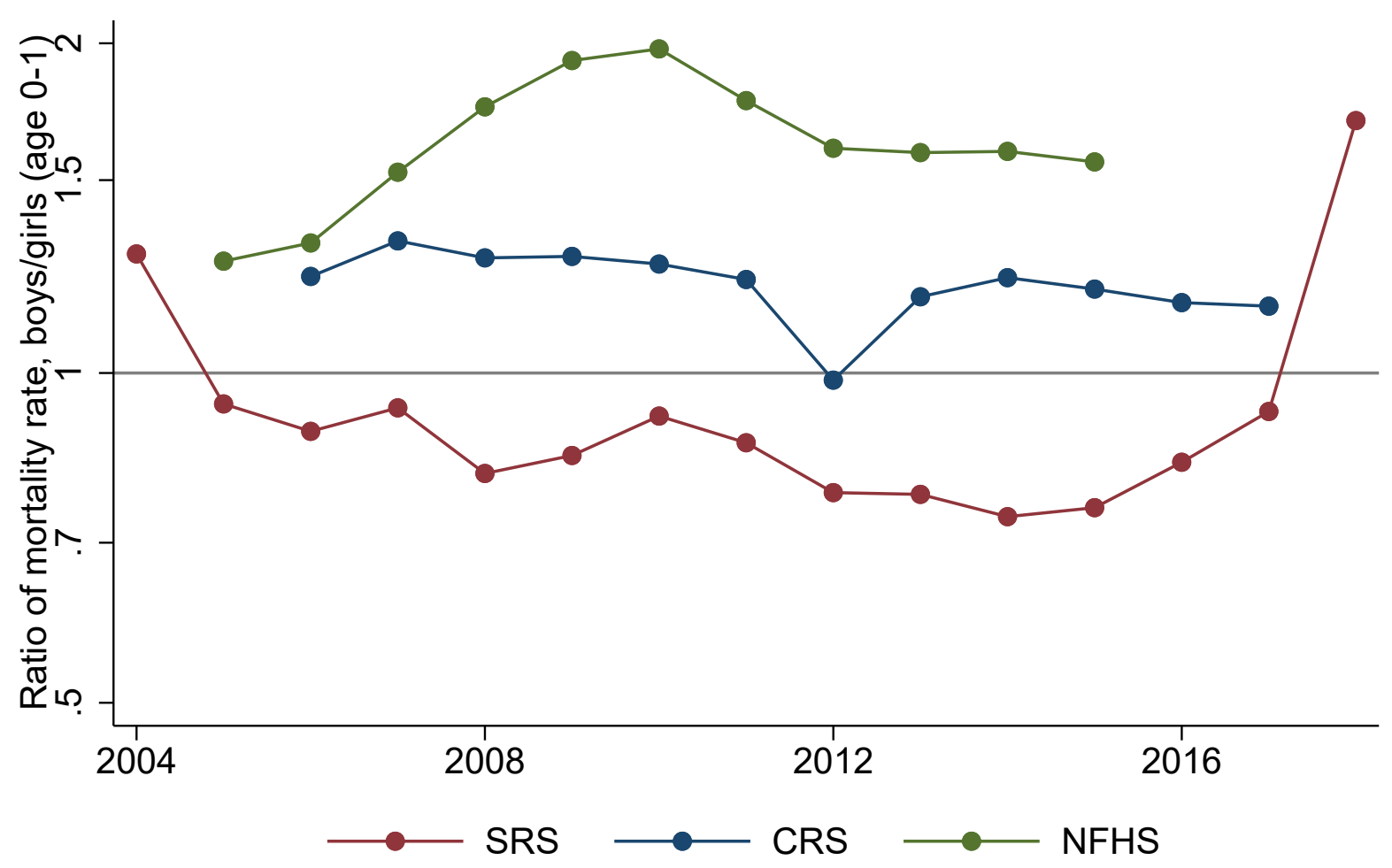

Ratio shown is mortality rate for boys divided by mortality rate for girls in ages 0-1. National Family Health Survey (NFHS) estimates are smoothed and reflect two-year moving averages. NFHS estimates are calculated by estimating person years lived and deaths in each year. Sample Registration System (SRS) estimates are from SRS annual reports. Civil Registration System (CRS) estimates are calculated from observed CRSdeaths and estimated mid-year population. 
Figure A4 Comparison of estimates of infant mortality rate from civil and sample registration systems

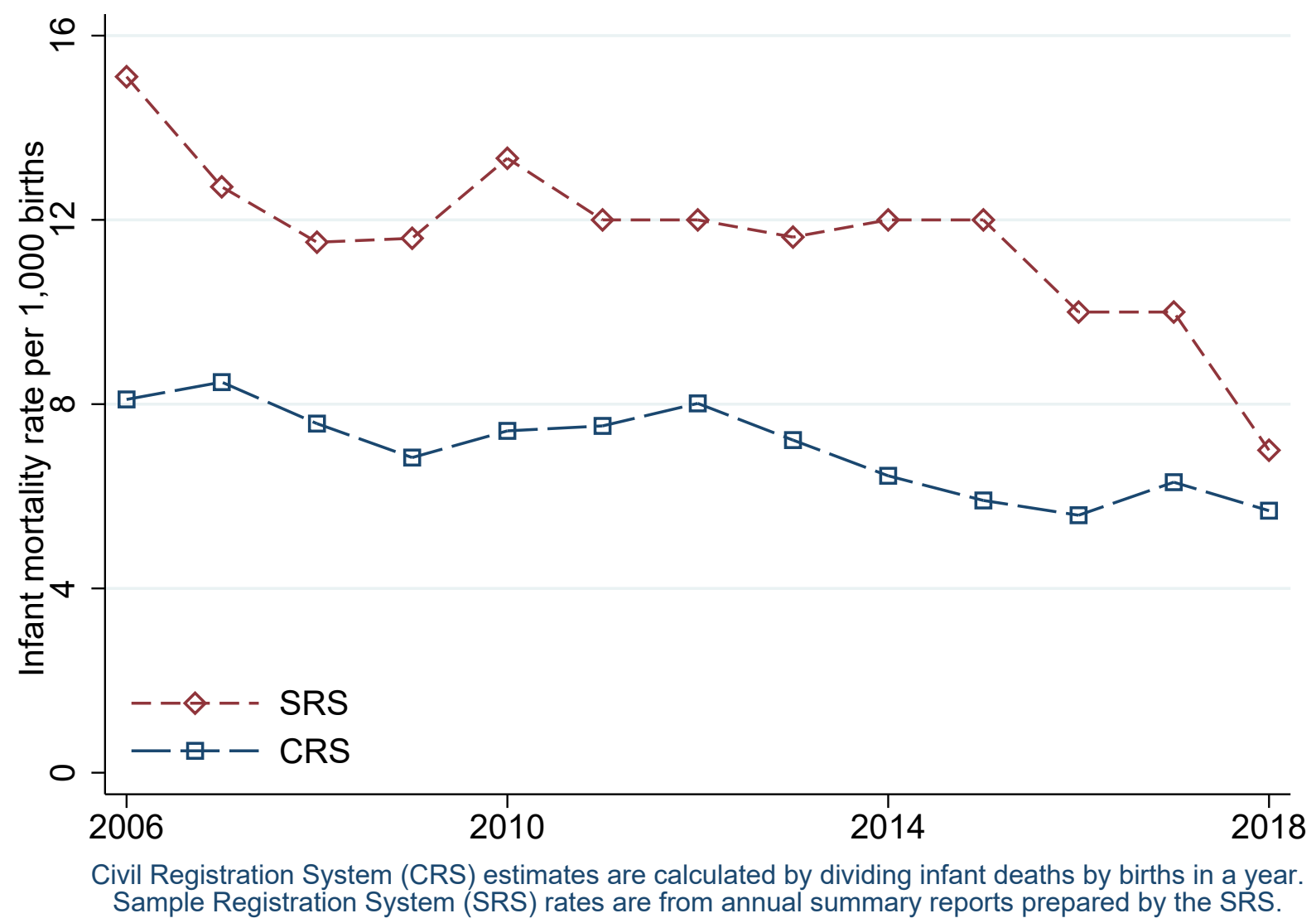


Figure A5 Comparison of three-year average estimates of ${ }_{n} \mathrm{~m}_{\mathrm{x}}$ from civil and sample registration systems
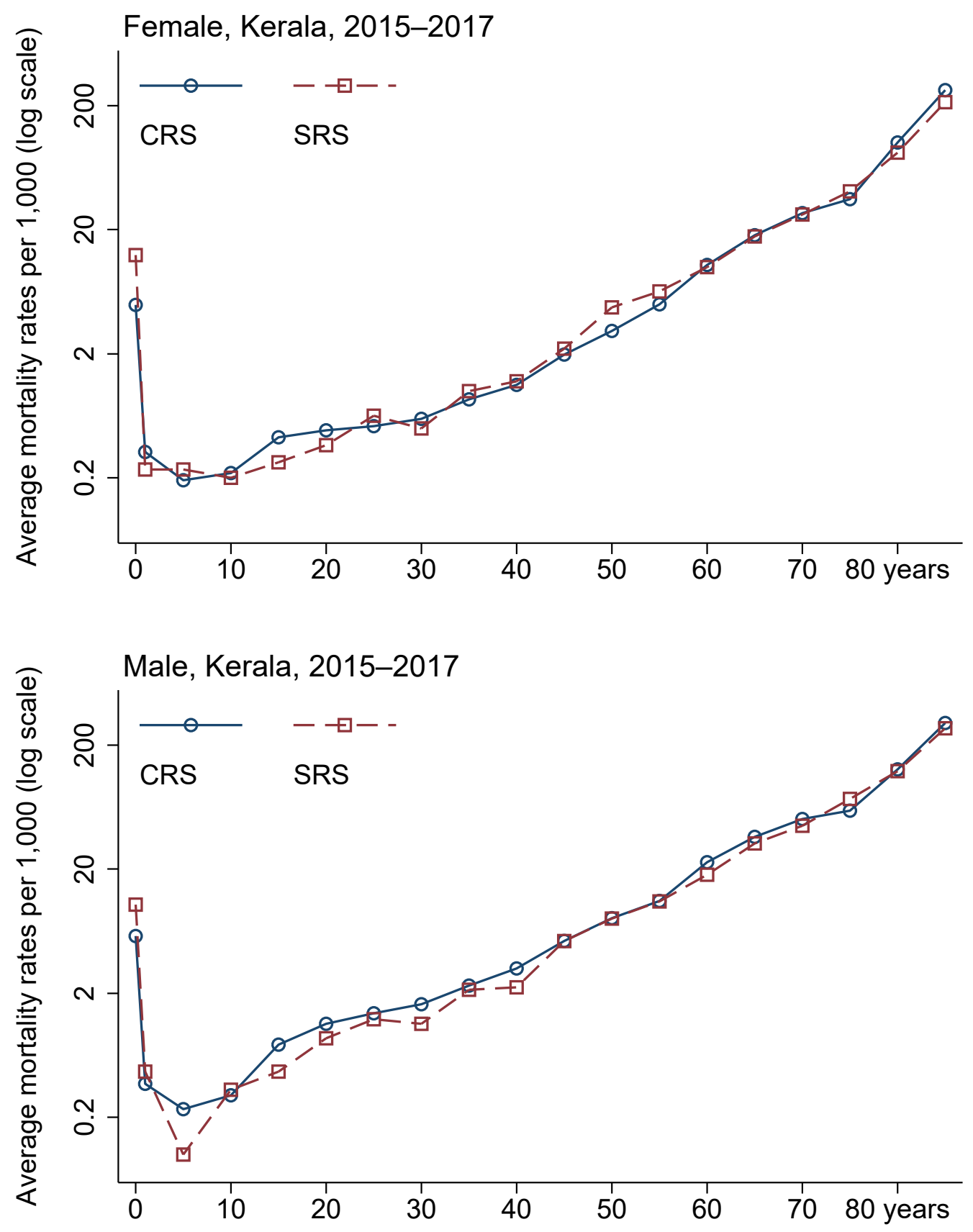

Sample Registration System (SRS) mortality rates are three-year averages from SRS statistical reports for 2015-2017. Civil Registration System (CRS) mortality rates are the three year average rates for 2015-2017. 
Figure A6 Comparison of five-year average estimates of ${ }_{n} m_{x}$ from civil and sample registration systems
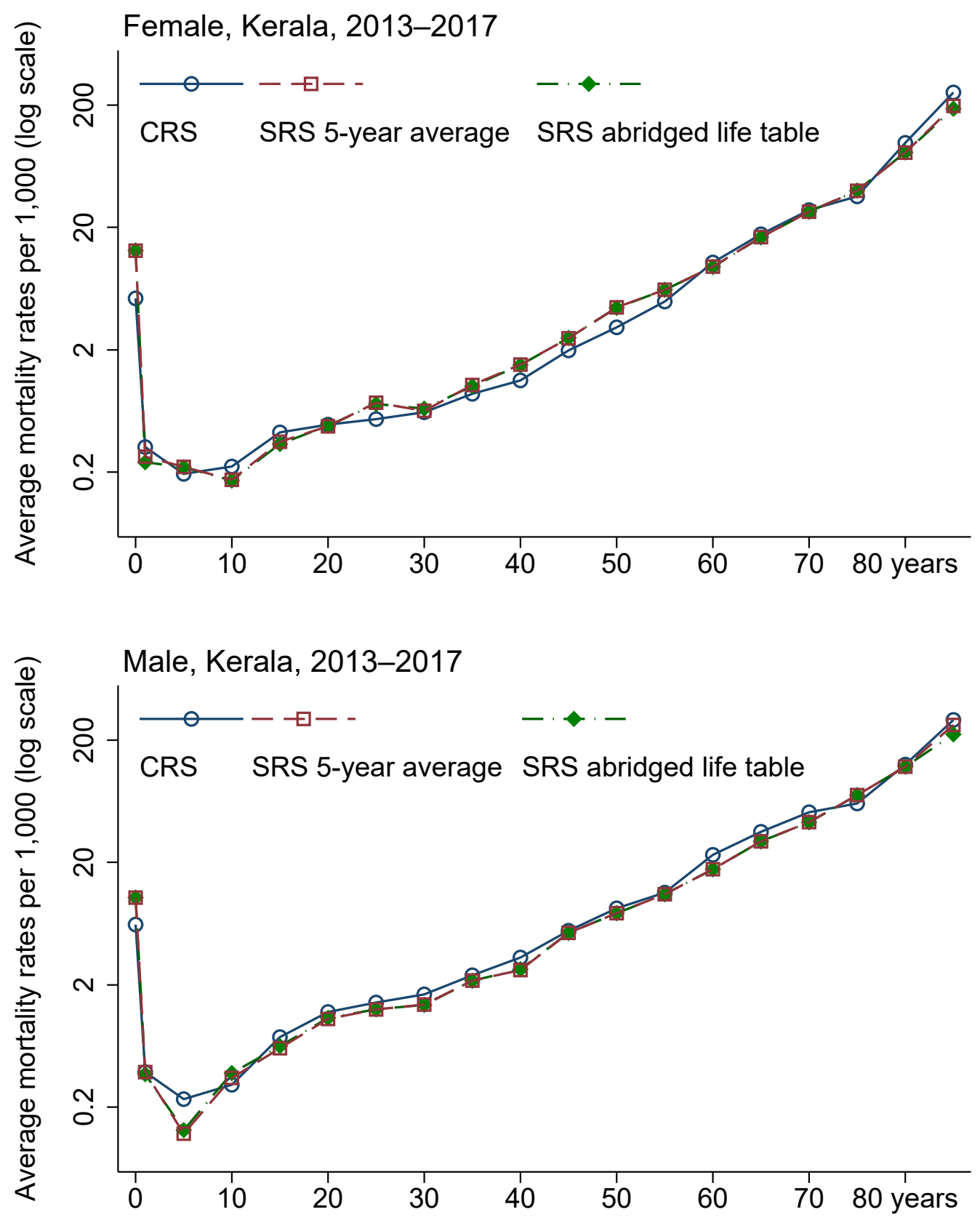

Sample Registration System (SRS) mortality rates are the five-year average rates calculated using annual SRS statistical reports for 2013-2017. Civil registration System (CRS) mortality rates are for the five-year period 2013-2017 and use population estimates calculated by the DHS Program (2020). The SRS abridged life table mortality rates are for 2013-2017. 
Figure A7 Census vs estimated exposures (2011, mid year)

Female, Kerala, 2011

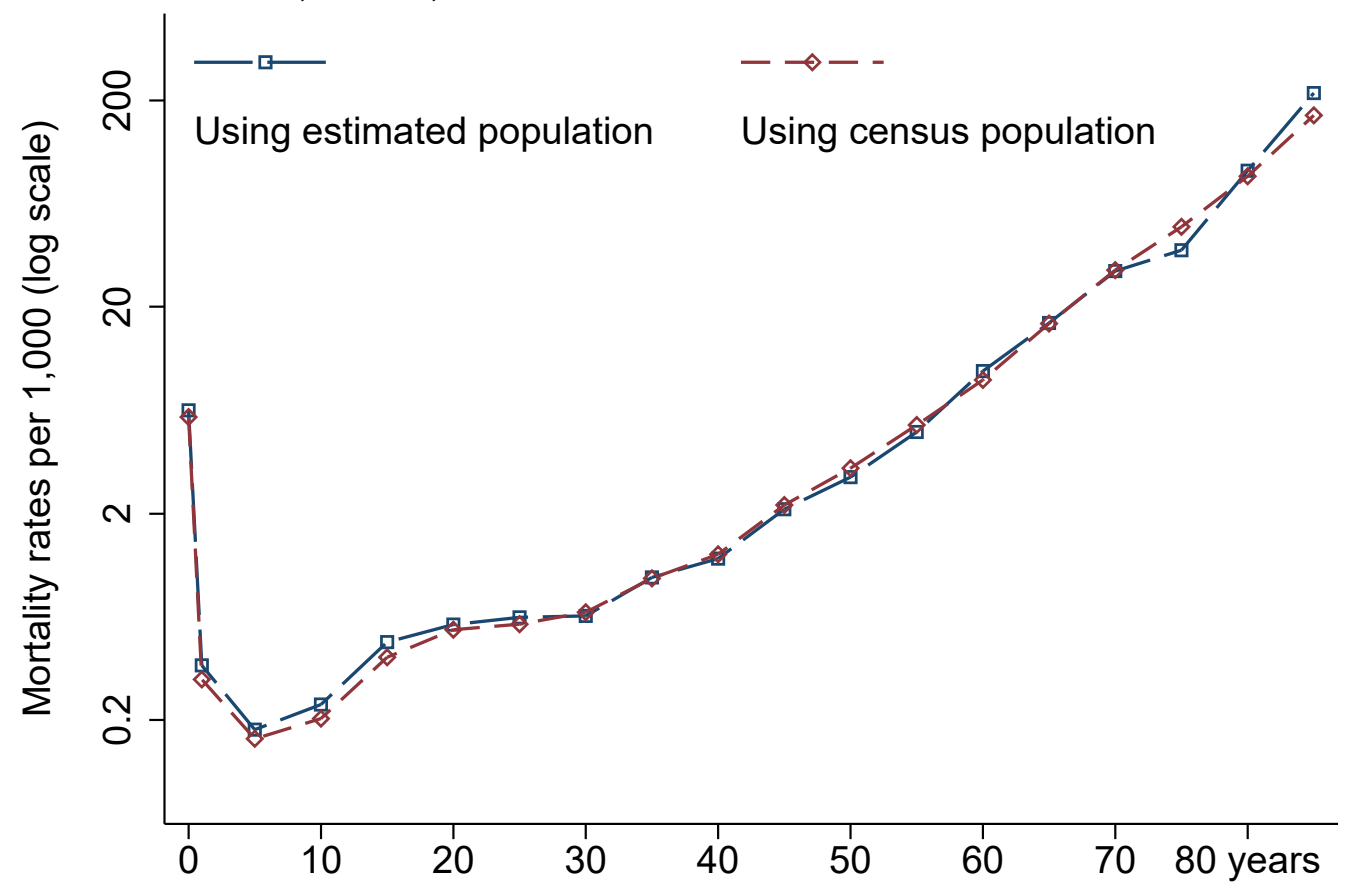

Male, Kerala, 2011

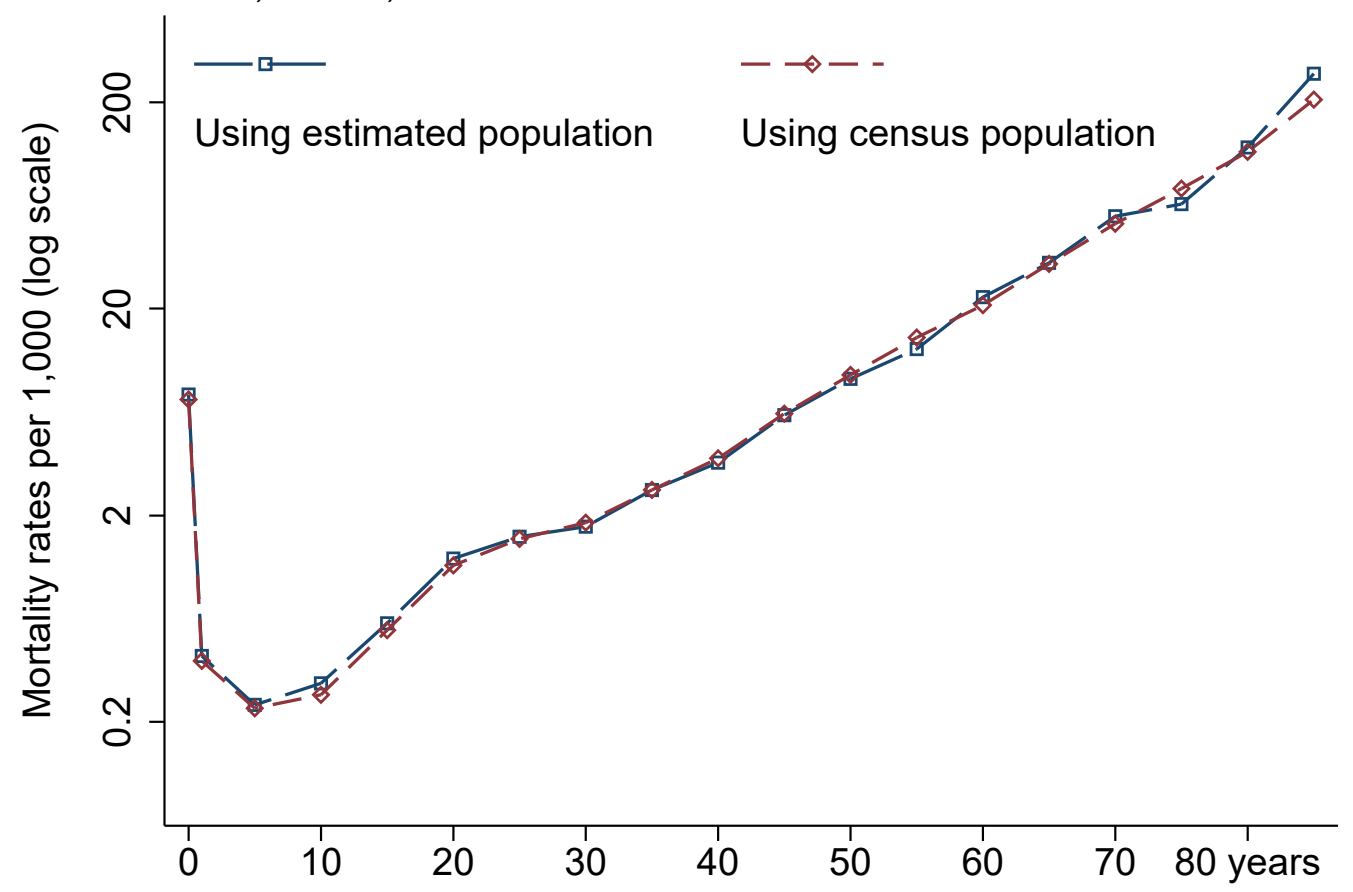

Estimated population rates are calculated by dividing deaths for the calendar year by the population estimated by the DHS Program (2020). Census population rates are calculated by dividing deaths from September 1, 2010 to August 31, 2011 by the 2011 census population. 
Figure A8 Official projections vs estimated exposures (2016)

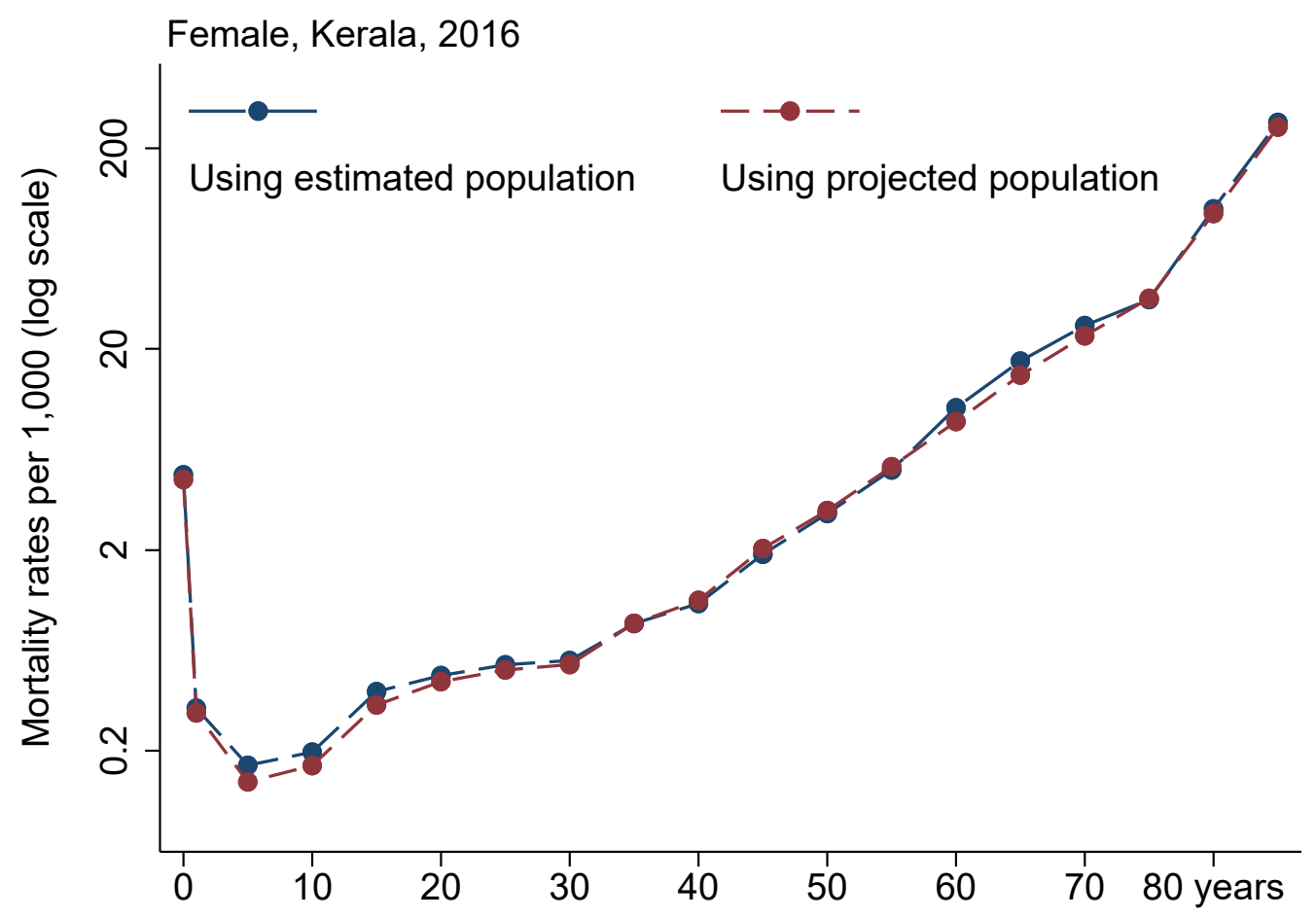

Male, Kerala, 2016

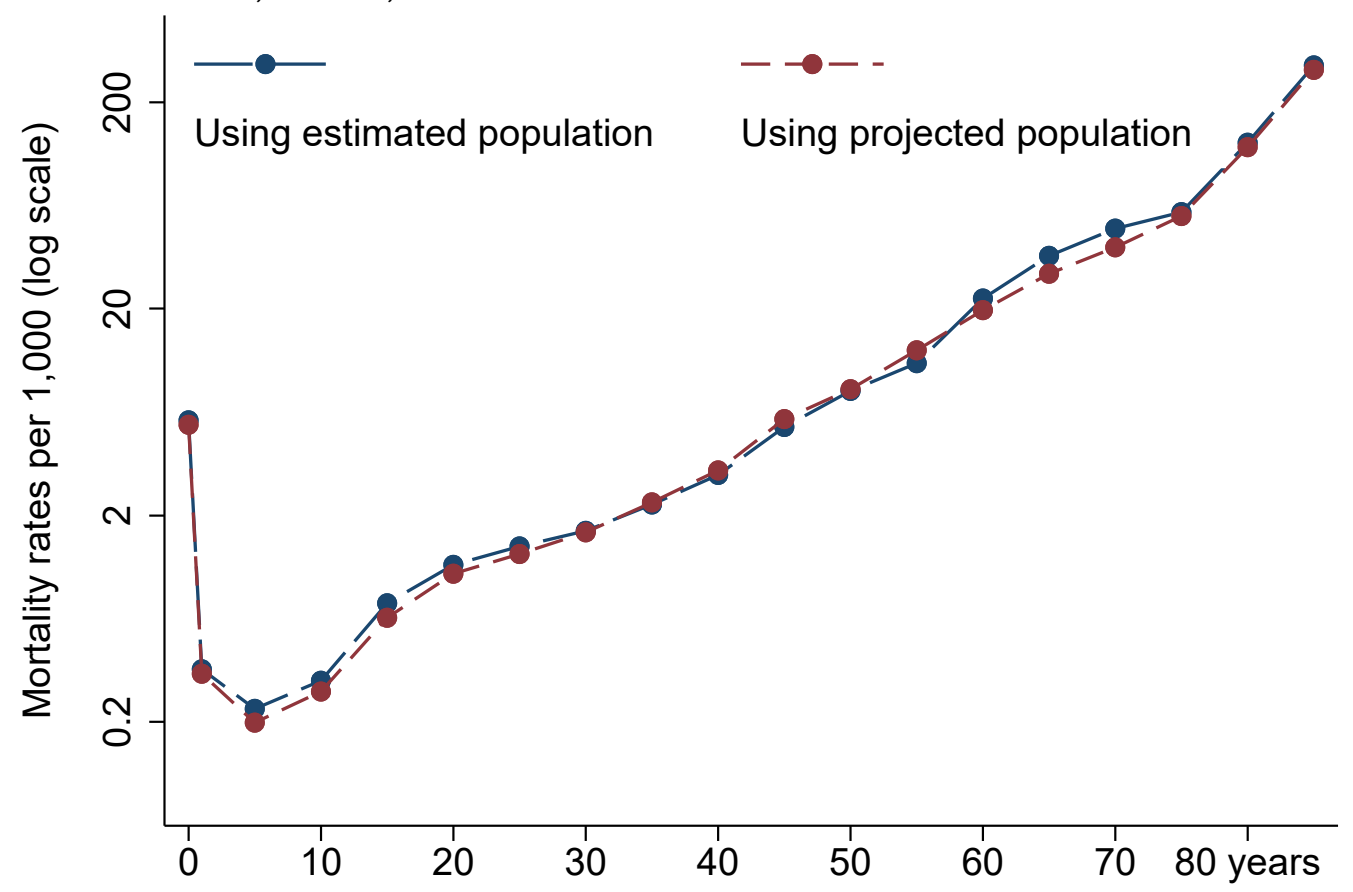

Estimated population rates are calculated by dividing deaths for the calendar year by the population estimated by the DHS Program (2020). Census population rates are calculated by dividing deaths for the calendar year by the projected census population for 2016. 
Figure A9 Age distribution of deaths, female, 2006-2017

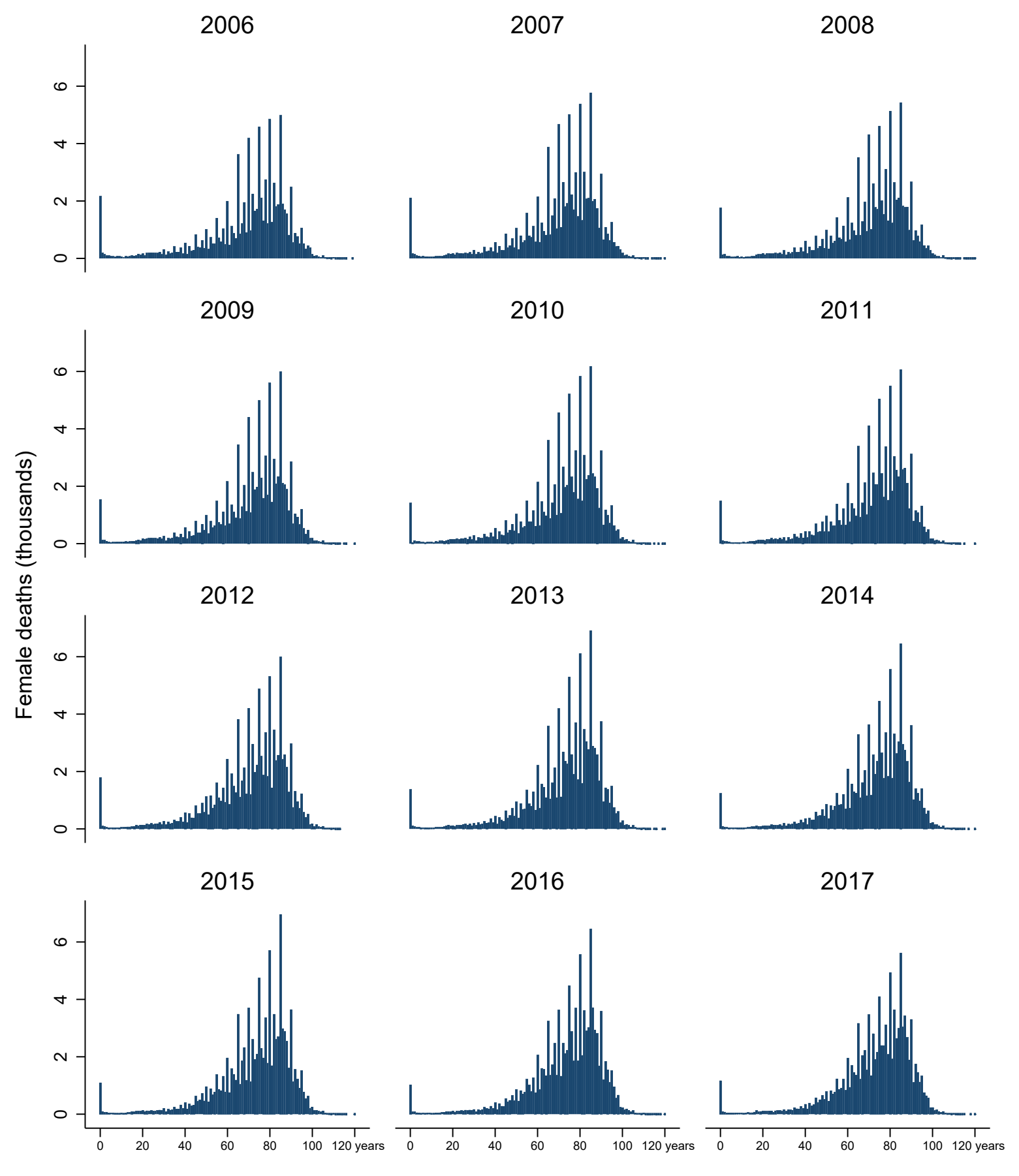

Individual-level death records from the Department of Economics and Statistics and the Department of Local Self-Government, Government of Kerala 
Figure A10 Age distribution of deaths, male, 2006-2017
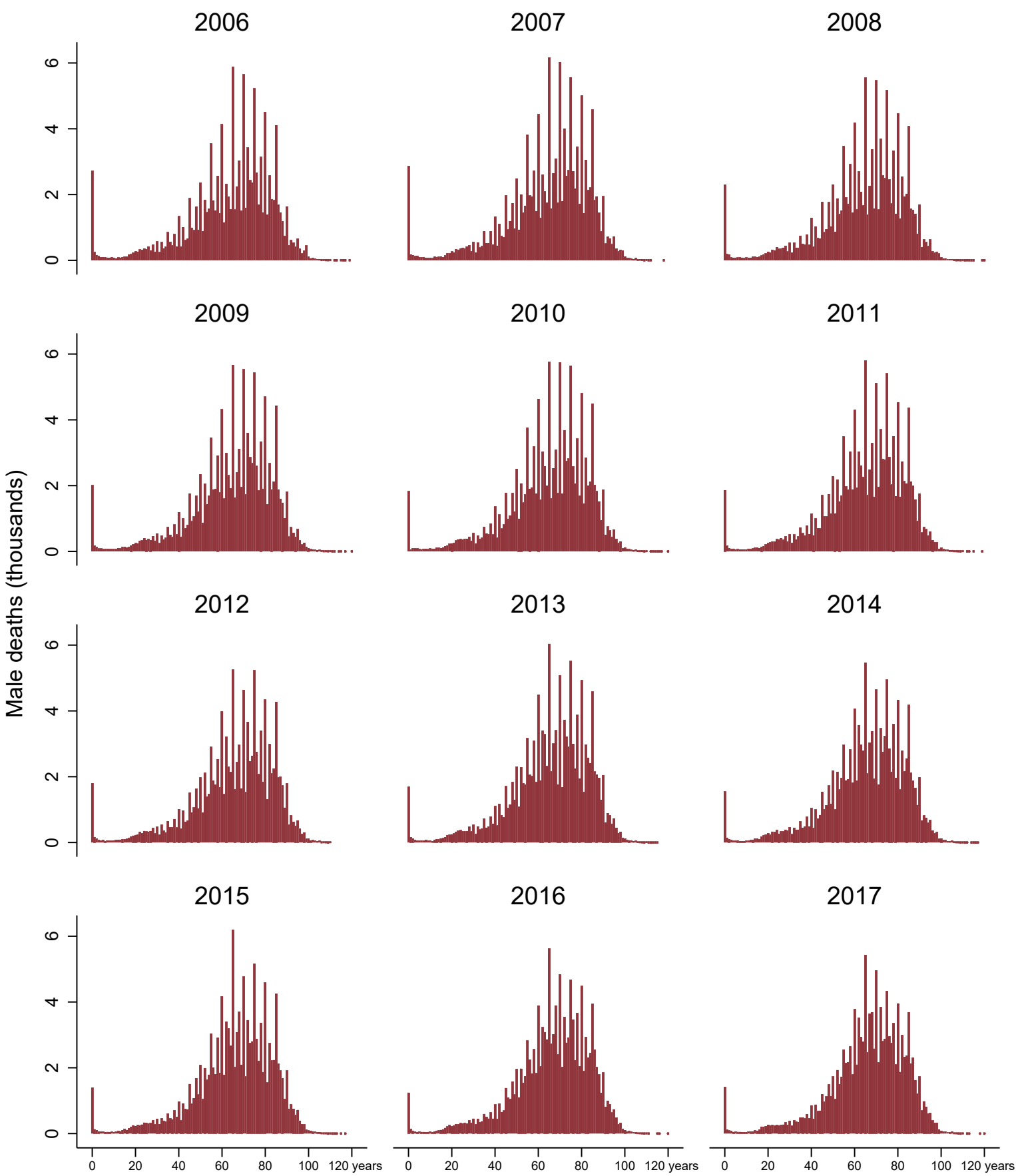

Individual-level death records from the Department of Economics and Statistics and the Department of Local Self-Government, Government of Kerala 
Figure A11 Age heaping: Myers blended index and Whipple index
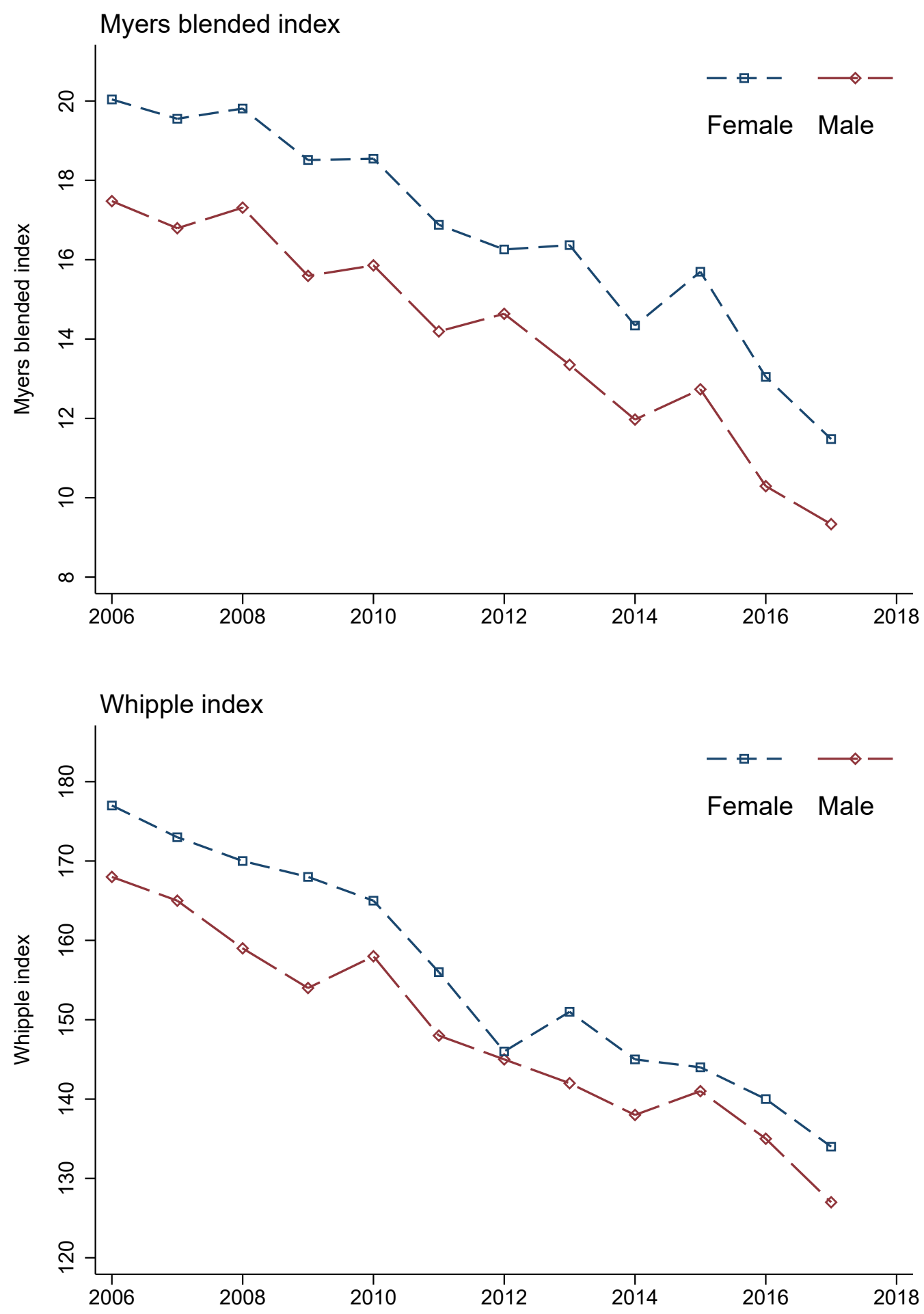

The Myers index considers preference of ages ending in each of the digits 0 to 9 . The index ranges from 0 to 90.0 indicates no age heaping and 90 indicates extreme age heaping. Whipple's index indicates the preference of ages ending in 0 or 5 for ages between 23 and 62 . The index ranges from 100 to 500, with 100 representing no digit preference. 


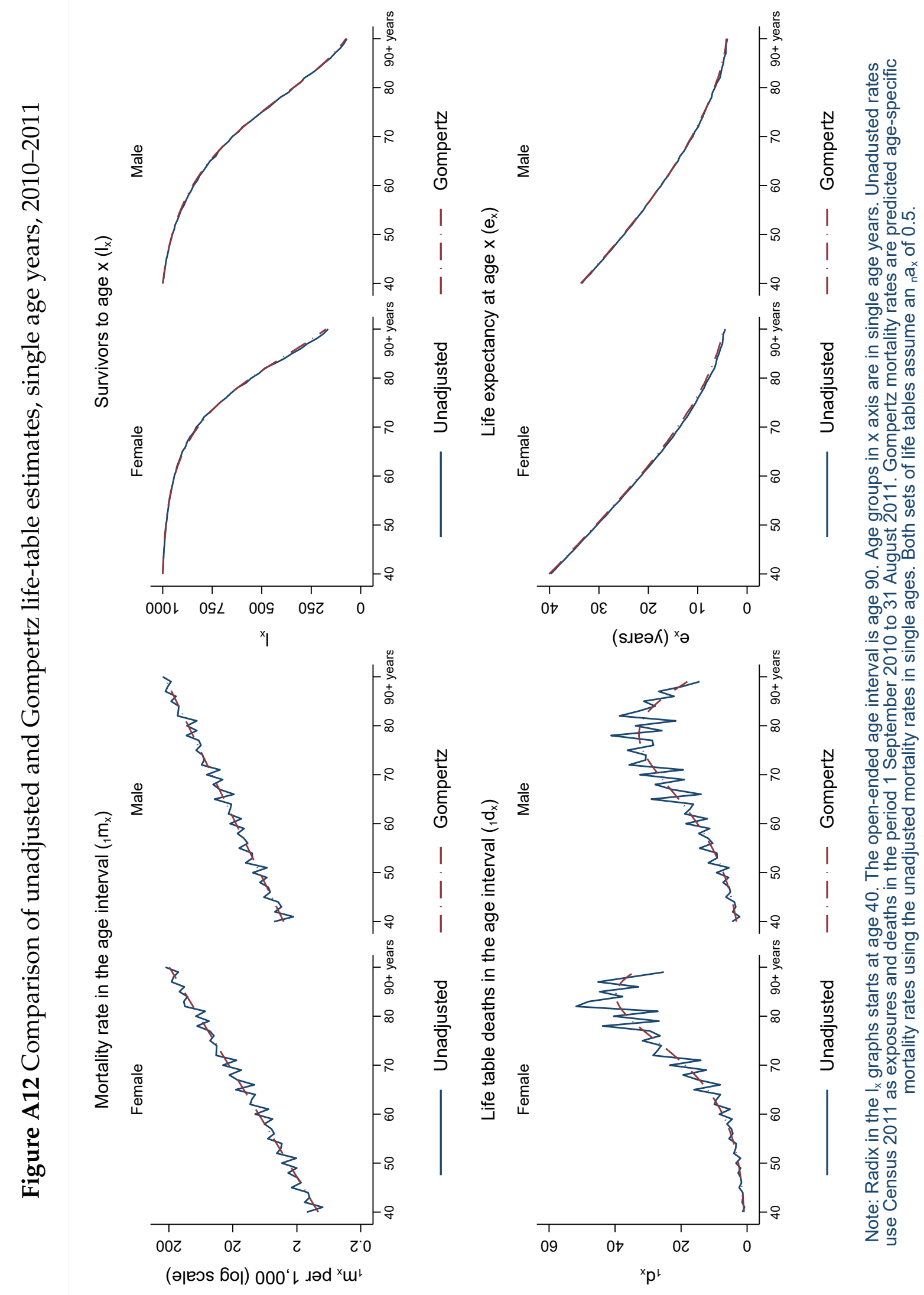


Figure A13 Comparison of the relationship between child and adult mortality in Kerala and Human Mortality Database countries

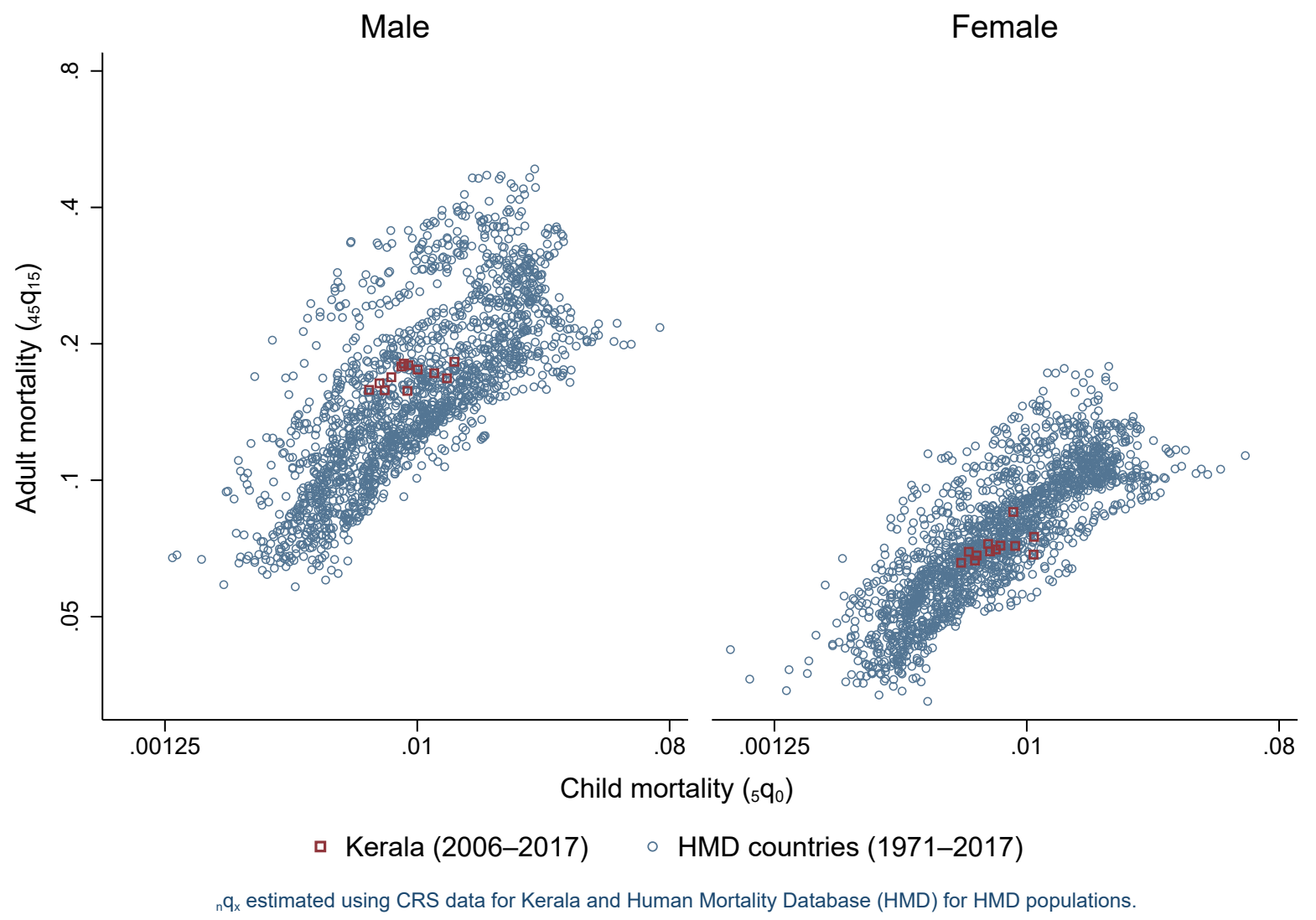


Figure A14 Comparison of the relationship between child and old-age mortality in Kerala and Human Mortality Database countries

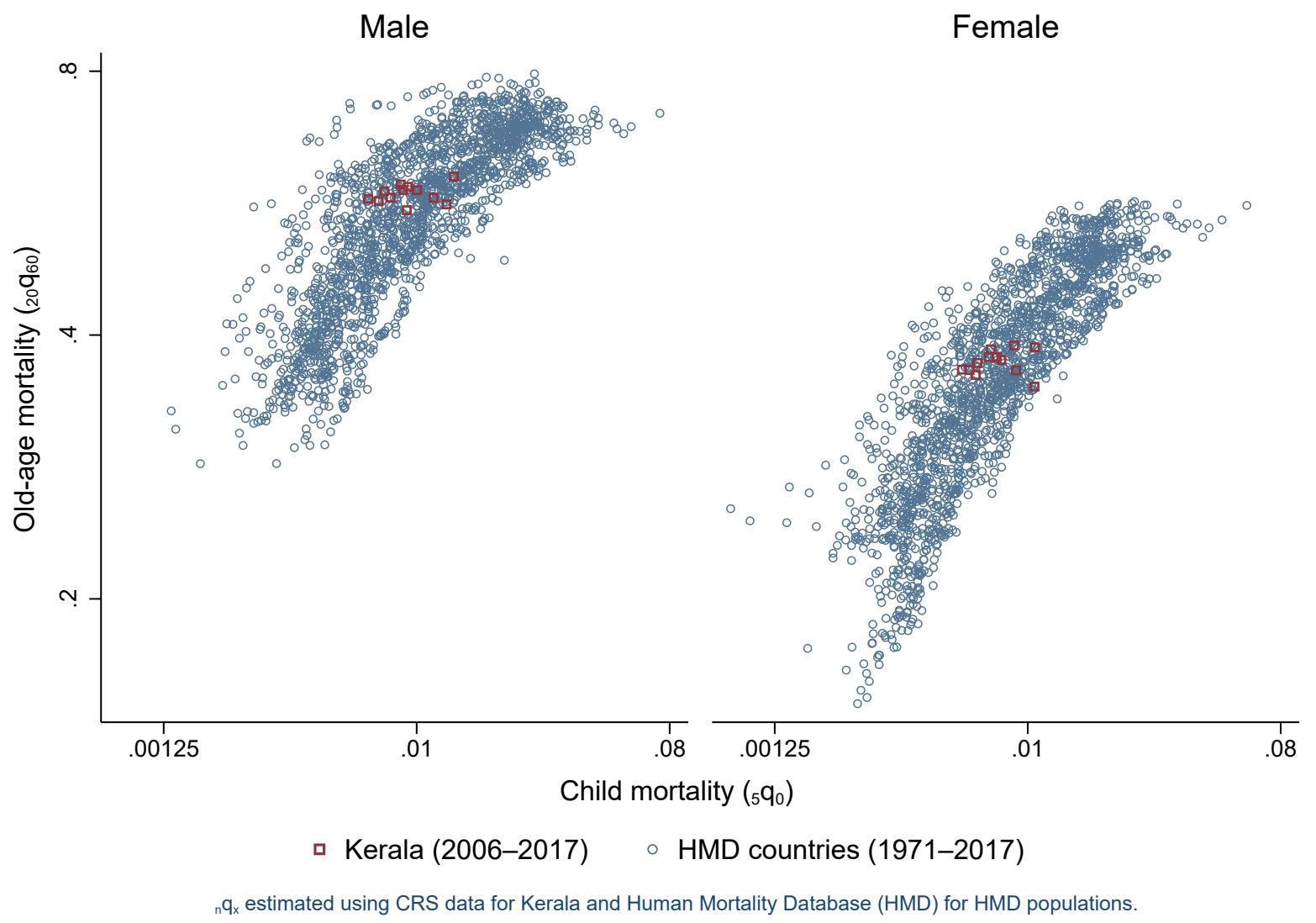


Table A1 Observations with missing data, 2006-2017

\begin{tabular}{ccccccc}
\hline Year & \multicolumn{3}{c}{ Only age (\%) } & Only sex & $\begin{array}{c}\text { Sex and age } \\
\%\end{array}$ & $\begin{array}{c}\text { Sex or age } \\
\%\end{array}$ \\
\cline { 2 - 4 } & Female & Male & Total & & & $\%$ \\
\hline 2006 & 0.03 & 0.02 & 0.02 & 1.97 & 0.00 & 1.99 \\
2007 & 0.49 & 0.41 & 0.44 & 1.23 & 0.00 & 1.66 \\
2008 & 0.53 & 0.52 & 0.52 & 0.61 & 0.00 & 1.13 \\
2009 & 0.68 & 0.64 & 0.66 & 0.32 & 0.01 & 0.98 \\
2010 & 0.86 & 0.84 & 0.85 & 0.06 & 0.02 & 0.91 \\
2011 & 0.70 & 0.63 & 0.66 & 0.01 & 0.01 & 0.67 \\
2012 & 0.57 & 0.52 & 0.54 & 0.01 & 0.00 & 0.55 \\
2013 & 0.50 & 0.45 & 0.47 & 0.01 & 0.00 & 0.48 \\
2014 & 0.45 & 0.39 & 0.41 & 0.01 & 0.00 & 0.42 \\
2015 & 0.49 & 0.46 & 0.47 & 0.01 & 0.00 & 0.48 \\
2016 & 0.49 & 0.44 & 0.46 & 0.00 & 0.00 & 0.46 \\
2017 & 0.32 & 0.31 & 0.31 & 0.01 & 0.00 & 0.32 \\
\hline
\end{tabular}

Note: Authors' calculations using data from the Kerala MARANAM Study and adjusted population estimates from the DHS Program (2020). Column 2 (3) refers to the share of female (male) deaths with missing age. Columns 4 to 7 refer to the share of total deaths with missing observations for the specified category. 
Table A2 Life tables, 2011

\begin{tabular}{|c|c|c|c|c|c|c|c|c|c|c|}
\hline \multirow[b]{2}{*}{ Age $x$} & \multicolumn{5}{|c|}{ Female } & \multicolumn{5}{|c|}{ Male } \\
\hline & ${ }_{n} m_{x}$ & ${ }_{n} q_{x}$ & $l_{x}$ & ${ }_{n} L_{x}$ & $e_{x}$ & ${ }_{n} m_{x}$ & ${ }_{n} q_{x}$ & $l_{x}$ & ${ }_{n} L_{x}$ & $e_{x}$ \\
\hline 0 & 0.0063 & 0.0063 & 1000 & 994.3 & 78.2 & 0.0077 & 0.0076 & 1000 & 992.9 & 70.9 \\
\hline 1 & 0.0004 & 0.0015 & 994 & 3971.2 & 77.7 & 0.0004 & 0.0017 & 992 & 3965.5 & 70.5 \\
\hline 5 & 0.0002 & 0.0009 & 992 & 4959.0 & 73.8 & 0.0002 & 0.0012 & 991 & 4950.5 & 66.6 \\
\hline 10 & 0.0002 & 0.0012 & 991 & 4953.9 & 68.9 & 0.0003 & 0.0015 & 990 & 4943.7 & 61.7 \\
\hline 15 & 0.0005 & 0.0024 & 990 & 4945.5 & 64.0 & 0.0006 & 0.0030 & 988 & 4933.5 & 56.7 \\
\hline 20 & 0.0006 & 0.0029 & 988 & 4932.1 & 59.1 & 0.0012 & 0.0062 & 985 & 4911.0 & 51.9 \\
\hline 25 & 0.0006 & 0.0031 & 985 & 4917.6 & 54.3 & 0.0016 & 0.0078 & 979 & 4876.0 & 47.2 \\
\hline 30 & 0.0006 & 0.0032 & 982 & 4901.9 & 49.4 & 0.0018 & 0.0088 & 971 & 4836.2 & 42.6 \\
\hline 35 & 0.0010 & 0.0049 & 979 & 4882.2 & 44.6 & 0.0027 & 0.0132 & 963 & 4784.1 & 37.9 \\
\hline 40 & 0.0012 & 0.0060 & 974 & 4856.3 & 39.8 & 0.0036 & 0.0178 & 950 & 4710.5 & 33.4 \\
\hline 45 & 0.0021 & 0.0104 & 968 & 4816.8 & 35.0 & 0.0061 & 0.0301 & 933 & 4599.6 & 28.9 \\
\hline 50 & 0.0030 & 0.0149 & 958 & 4756.5 & 30.4 & 0.0092 & 0.0449 & 905 & 4429.2 & 24.8 \\
\hline 55 & 0.0050 & 0.0245 & 944 & 4665.5 & 25.8 & 0.0128 & 0.0621 & 864 & 4196.1 & 20.8 \\
\hline 60 & 0.0098 & 0.0479 & 921 & 4501.7 & 21.4 & 0.0228 & 0.1082 & 811 & 3846.2 & 17.0 \\
\hline 65 & 0.0167 & 0.0806 & 876 & 4220.4 & 17.3 & 0.0334 & 0.1549 & 723 & 3349.3 & 13.7 \\
\hline 70 & 0.0299 & 0.1397 & 806 & 3766.8 & 13.6 & 0.0562 & 0.2477 & 611 & 2691.7 & 10.8 \\
\hline 75 & 0.0377 & 0.1732 & 693 & 3182.4 & 10.3 & 0.0644 & 0.2776 & 460 & 1981.9 & 8.5 \\
\hline 80 & 0.0915 & 0.3740 & 573 & 2341.8 & 7.0 & 0.1212 & 0.4625 & 332 & 1267.4 & 5.8 \\
\hline 85 & 0.2178 & 1.0000 & 359 & 1647.5 & 4.6 & 0.2758 & 1.0000 & 178 & 647.2 & 3.6 \\
\hline
\end{tabular}

Note: Authors' calculations using data from the Kerala MARANAM Study and adjusted population estimates from DHS Program (2020). 
Table A3 Life tables, 2012

\begin{tabular}{|c|c|c|c|c|c|c|c|c|c|c|}
\hline \multirow[b]{2}{*}{ Age $x$} & \multicolumn{5}{|c|}{ Female } & \multicolumn{5}{|c|}{ Male } \\
\hline & ${ }_{n} m_{x}$ & ${ }_{n} q_{x}$ & $l_{x}$ & ${ }_{n} L_{x}$ & $e_{x}$ & ${ }_{n} m_{x}$ & ${ }_{n} q_{x}$ & $l_{x}$ & ${ }_{n} L_{x}$ & $e_{x}$ \\
\hline 0 & 0.0077 & 0.0077 & 1000 & 993.0 & 77.5 & 0.0076 & 0.0076 & 1000 & 993.0 & 72.3 \\
\hline 1 & 0.0003 & 0.0013 & 992 & 3966.1 & 77.1 & 0.0004 & 0.0017 & 992 & 3965.8 & 71.8 \\
\hline 5 & 0.0002 & 0.0010 & 991 & 4952.7 & 73.2 & 0.0002 & 0.0011 & 991 & 4951.1 & 67.9 \\
\hline 10 & 0.0003 & 0.0014 & 990 & 4946.6 & 68.3 & 0.0003 & 0.0016 & 990 & 4944.3 & 63.0 \\
\hline 15 & 0.0005 & 0.0024 & 989 & 4937.7 & 63.3 & 0.0006 & 0.0030 & 988 & 4933.8 & 58.1 \\
\hline 20 & 0.0006 & 0.0032 & 986 & 4924.0 & 58.5 & 0.0011 & 0.0057 & 985 & 4912.3 & 53.3 \\
\hline 25 & 0.0007 & 0.0035 & 983 & 4907.7 & 53.7 & 0.0014 & 0.0072 & 979 & 4880.1 & 48.6 \\
\hline 30 & 0.0008 & 0.0040 & 980 & 4889.3 & 48.8 & 0.0016 & 0.0078 & 972 & 4843.9 & 43.9 \\
\hline 35 & 0.0011 & 0.0054 & 976 & 4866.6 & 44.0 & 0.0023 & 0.0113 & 965 & 4798.3 & 39.2 \\
\hline 40 & 0.0015 & 0.0075 & 971 & 4836.1 & 39.3 & 0.0032 & 0.0157 & 954 & 4734.2 & 34.6 \\
\hline 45 & 0.0026 & 0.0129 & 963 & 4787.7 & 34.5 & 0.0053 & 0.0263 & 939 & 4636.4 & 30.2 \\
\hline 50 & 0.0038 & 0.0189 & 951 & 4712.5 & 29.9 & 0.0079 & 0.0387 & 914 & 4488.1 & 25.9 \\
\hline 55 & 0.0062 & 0.0306 & 933 & 4599.2 & 25.5 & 0.0108 & 0.0527 & 879 & 4286.0 & 21.8 \\
\hline 60 & 0.0119 & 0.0579 & 904 & 4402.0 & 21.2 & 0.0204 & 0.0973 & 833 & 3971.0 & 17.9 \\
\hline 65 & 0.0184 & 0.0883 & 852 & 4087.5 & 17.3 & 0.0300 & 0.1400 & 752 & 3507.5 & 14.5 \\
\hline 70 & 0.0303 & 0.1416 & 777 & 3627.6 & 13.7 & 0.0491 & 0.2197 & 646 & 2891.2 & 11.5 \\
\hline 75 & 0.0373 & 0.1715 & 667 & 3063.8 & 10.6 & 0.0612 & 0.2659 & 504 & 2192.4 & 9.0 \\
\hline 80 & 0.0883 & 0.3632 & 553 & 2272.1 & 7.2 & 0.1177 & 0.4528 & 370 & 1424.4 & 6.3 \\
\hline 85 & 0.2056 & 1.0000 & 352 & 1711.1 & 4.9 & 0.2216 & 1.0000 & 203 & 914.3 & 4.5 \\
\hline
\end{tabular}

Note: Authors' calculations using data from the Kerala MARANAM Study and adjusted population estimates from the DHS Program (2020). 
Table A4 Life tables, 2013

\begin{tabular}{|c|c|c|c|c|c|c|c|c|c|c|}
\hline \multirow[b]{2}{*}{ Age $x$} & \multicolumn{5}{|c|}{ Female } & \multicolumn{5}{|c|}{ Male } \\
\hline & ${ }_{n} m_{x}$ & ${ }_{n} q_{x}$ & $l_{x}$ & ${ }_{n} L_{x}$ & $e_{x}$ & ${ }_{n} m_{x}$ & ${ }_{n} q_{x}$ & $l_{x}$ & ${ }_{n} L_{x}$ & $e_{x}$ \\
\hline 0 & 0.0061 & 0.0060 & 1000 & 994.5 & 78.0 & 0.0071 & 0.0071 & 1000 & 993.4 & 70.8 \\
\hline 1 & 0.0003 & 0.0014 & 994 & 3972.5 & 77.5 & 0.0004 & 0.0017 & 993 & 3967.7 & 70.3 \\
\hline 5 & 0.0002 & 0.0010 & 993 & 4960.5 & 73.6 & 0.0002 & 0.0012 & 991 & 4953.1 & 66.5 \\
\hline 10 & 0.0002 & 0.0012 & 992 & 4955.1 & 68.7 & 0.0003 & 0.0015 & 990 & 4946.2 & 61.5 \\
\hline 15 & 0.0004 & 0.0022 & 990 & 4947.3 & 63.8 & 0.0007 & 0.0035 & 988 & 4934.6 & 56.6 \\
\hline 20 & 0.0005 & 0.0025 & 988 & 4935.5 & 58.9 & 0.0013 & 0.0065 & 985 & 4909.8 & 51.8 \\
\hline 25 & 0.0006 & 0.0031 & 986 & 4922.0 & 54.0 & 0.0016 & 0.0078 & 979 & 4874.4 & 47.1 \\
\hline 30 & 0.0007 & 0.0034 & 983 & 4906.2 & 49.2 & 0.0018 & 0.0089 & 971 & 4834.7 & 42.5 \\
\hline 35 & 0.0009 & 0.0047 & 980 & 4886.5 & 44.3 & 0.0026 & 0.0129 & 962 & 4782.8 & 37.8 \\
\hline 40 & 0.0011 & 0.0057 & 975 & 4861.6 & 39.5 & 0.0038 & 0.0186 & 950 & 4708.4 & 33.3 \\
\hline 45 & 0.0020 & 0.0100 & 969 & 4824.5 & 34.8 & 0.0061 & 0.0302 & 932 & 4595.9 & 28.9 \\
\hline 50 & 0.0031 & 0.0155 & 960 & 4763.5 & 30.1 & 0.0092 & 0.0450 & 904 & 4425.7 & 24.7 \\
\hline 55 & 0.0050 & 0.0246 & 945 & 4669.4 & 25.5 & 0.0122 & 0.0593 & 863 & 4197.8 & 20.7 \\
\hline 60 & 0.0105 & 0.0512 & 921 & 4497.8 & 21.1 & 0.0239 & 0.1129 & 812 & 3844.6 & 16.9 \\
\hline 65 & 0.0173 & 0.0831 & 874 & 4203.6 & 17.1 & 0.0349 & 0.1612 & 721 & 3325.5 & 13.7 \\
\hline 70 & 0.0300 & 0.1403 & 802 & 3744.9 & 13.4 & 0.0541 & 0.2396 & 604 & 2674.9 & 10.8 \\
\hline 75 & 0.0389 & 0.1780 & 689 & 3156.2 & 10.1 & 0.0655 & 0.2825 & 460 & 1981.0 & 8.4 \\
\hline 80 & 0.0938 & 0.3819 & 566 & 2305.5 & 6.8 & 0.1261 & 0.4777 & 330 & 1249.2 & 5.7 \\
\hline 85 & 0.2298 & 1.0000 & 350 & 1523.3 & 4.4 & 0.2732 & 1.0000 & 172 & 630.4 & 3.7 \\
\hline
\end{tabular}

Note: Authors' calculations using data from the Kerala MARANAM Study and adjusted population estimates from the DHS Program (2020). 
Table A5 Life tables, 2014

\begin{tabular}{|c|c|c|c|c|c|c|c|c|c|c|}
\hline \multirow[b]{2}{*}{ Age $x$} & \multicolumn{5}{|c|}{ Female } & \multicolumn{5}{|c|}{ Male } \\
\hline & ${ }_{n} m_{x}$ & ${ }_{n} q_{x}$ & $l_{x}$ & ${ }_{n} L_{x}$ & $e_{x}$ & ${ }_{n} m_{x}$ & ${ }_{n} q_{x}$ & $l_{x}$ & ${ }_{n} L_{x}$ & $e_{x}$ \\
\hline 0 & 0.0054 & 0.0054 & 1000 & 995.1 & 78.4 & 0.0066 & 0.0066 & 1000 & 993.9 & 71.4 \\
\hline 1 & 0.0003 & 0.0012 & 995 & 3975.6 & 77.9 & 0.0004 & 0.0015 & 993 & 3970.2 & 70.8 \\
\hline 5 & 0.0002 & 0.0009 & 993 & 4965.0 & 73.9 & 0.0002 & 0.0011 & 992 & 4956.9 & 66.9 \\
\hline 10 & 0.0002 & 0.0011 & 993 & 4959.9 & 69.0 & 0.0003 & 0.0016 & 991 & 4950.3 & 62.0 \\
\hline 15 & 0.0004 & 0.0020 & 991 & 4952.5 & 64.1 & 0.0007 & 0.0036 & 989 & 4938.4 & 57.1 \\
\hline 20 & 0.0005 & 0.0025 & 989 & 4941.4 & 59.2 & 0.0013 & 0.0064 & 986 & 4913.9 & 52.3 \\
\hline 25 & 0.0005 & 0.0026 & 987 & 4928.7 & 54.4 & 0.0015 & 0.0073 & 979 & 4879.8 & 47.6 \\
\hline 30 & 0.0006 & 0.0031 & 984 & 4914.4 & 49.5 & 0.0017 & 0.0083 & 972 & 4842.0 & 42.9 \\
\hline 35 & 0.0009 & 0.0042 & 981 & 4896.8 & 44.6 & 0.0025 & 0.0122 & 964 & 4792.8 & 38.3 \\
\hline 40 & 0.0011 & 0.0055 & 977 & 4873.3 & 39.8 & 0.0035 & 0.0172 & 952 & 4723.9 & 33.7 \\
\hline 45 & 0.0020 & 0.0098 & 972 & 4837.1 & 35.0 & 0.0057 & 0.0283 & 936 & 4619.3 & 29.3 \\
\hline 50 & 0.0030 & 0.0148 & 962 & 4778.4 & 30.3 & 0.0089 & 0.0435 & 910 & 4454.8 & 25.0 \\
\hline 55 & 0.0048 & 0.0238 & 948 & 4687.6 & 25.8 & 0.0113 & 0.0549 & 870 & 4238.6 & 21.1 \\
\hline 60 & 0.0100 & 0.0490 & 926 & 4523.1 & 21.3 & 0.0234 & 0.1111 & 822 & 3897.1 & 17.1 \\
\hline 65 & 0.0166 & 0.0798 & 880 & 4239.1 & 17.3 & 0.0336 & 0.1558 & 731 & 3383.5 & 13.9 \\
\hline 70 & 0.0272 & 0.1276 & 810 & 3805.1 & 13.5 & 0.0511 & 0.2277 & 617 & 2748.2 & 11.0 \\
\hline 75 & 0.0351 & 0.1620 & 707 & 3262.9 & 10.1 & 0.0608 & 0.2649 & 477 & 2076.5 & 8.5 \\
\hline 80 & 0.0958 & 0.3879 & 592 & 2398.8 & 6.6 & 0.1226 & 0.4677 & 350 & 1336.4 & 5.7 \\
\hline 85 & 0.2413 & 1.0000 & 362 & 1502.4 & 4.1 & 0.2886 & 1.0000 & 186 & 646.1 & 3.5 \\
\hline
\end{tabular}

Note: Authors' calculations using data from the Kerala MARANAM Study and adjusted population estimates from the DHS Program (2020). 
Table A6 Life tables, 2015

\begin{tabular}{|c|c|c|c|c|c|c|c|c|c|c|}
\hline \multirow[b]{2}{*}{ Age $x$} & \multicolumn{5}{|c|}{ Female } & \multicolumn{5}{|c|}{ Male } \\
\hline & ${ }_{n} m_{x}$ & ${ }_{n} q_{x}$ & $l_{x}$ & ${ }_{n} L_{x}$ & $e_{x}$ & ${ }_{n} m_{x}$ & ${ }_{n} q_{x}$ & $l_{x}$ & ${ }_{n} L_{x}$ & $e_{x}$ \\
\hline 0 & 0.0049 & 0.0049 & 1000 & 995.5 & 78.2 & 0.0059 & 0.0058 & 1000 & 994.6 & 71.6 \\
\hline 1 & 0.0003 & 0.0013 & 995 & 3977.2 & 77.5 & 0.0004 & 0.0015 & 994 & 3973.1 & 71.0 \\
\hline 5 & 0.0002 & 0.0008 & 994 & 4966.9 & 73.6 & 0.0002 & 0.0011 & 993 & 4960.6 & 67.1 \\
\hline 10 & 0.0002 & 0.0011 & 993 & 4962.0 & 68.7 & 0.0003 & 0.0015 & 992 & 4954.2 & 62.2 \\
\hline 15 & 0.0004 & 0.0022 & 992 & 4954.1 & 63.8 & 0.0007 & 0.0037 & 990 & 4942.1 & 57.3 \\
\hline 20 & 0.0005 & 0.0025 & 990 & 4942.3 & 58.9 & 0.0011 & 0.0055 & 986 & 4919.4 & 52.5 \\
\hline 25 & 0.0005 & 0.0026 & 987 & 4929.4 & 54.0 & 0.0014 & 0.0070 & 981 & 4888.1 & 47.8 \\
\hline 30 & 0.0006 & 0.0031 & 985 & 4915.3 & 49.2 & 0.0017 & 0.0084 & 974 & 4850.9 & 43.1 \\
\hline 35 & 0.0009 & 0.0044 & 981 & 4897.4 & 44.3 & 0.0024 & 0.0118 & 966 & 4802.7 & 38.4 \\
\hline 40 & 0.0011 & 0.0056 & 977 & 4873.2 & 39.5 & 0.0033 & 0.0162 & 955 & 4736.9 & 33.9 \\
\hline 45 & 0.0020 & 0.0101 & 972 & 4836.0 & 34.7 & 0.0054 & 0.0268 & 939 & 4637.7 & 29.4 \\
\hline 50 & 0.0032 & 0.0157 & 962 & 4774.2 & 30.1 & 0.0084 & 0.0410 & 914 & 4481.0 & 25.1 \\
\hline 55 & 0.0051 & 0.0252 & 947 & 4677.6 & 25.5 & 0.0113 & 0.0552 & 876 & 4268.6 & 21.1 \\
\hline 60 & 0.0100 & 0.0490 & 923 & 4509.8 & 21.1 & 0.0229 & 0.1085 & 828 & 3931.1 & 17.2 \\
\hline 65 & 0.0180 & 0.0863 & 878 & 4212.8 & 17.0 & 0.0357 & 0.1645 & 738 & 3402.4 & 13.9 \\
\hline 70 & 0.0271 & 0.1272 & 802 & 3767.6 & 13.4 & 0.0492 & 0.2200 & 617 & 2757.4 & 11.1 \\
\hline 75 & 0.0352 & 0.1627 & 700 & 3231.9 & 9.9 & 0.0588 & 0.2574 & 481 & 2104.6 & 8.6 \\
\hline 80 & 0.0986 & 0.3975 & 586 & 2362.2 & 6.4 & 0.1235 & 0.4702 & 357 & 1360.6 & 5.6 \\
\hline 85 & 0.2583 & 1.0000 & 353 & 1367.2 & 3.9 & 0.2909 & 1.0000 & 189 & 650.8 & 3.4 \\
\hline
\end{tabular}

Note: Authors' calculations using data from the Kerala MARANAM Study and adjusted population estimates from the DHS Program (2020). 
Table A7 Life tables, 2016

\begin{tabular}{|c|c|c|c|c|c|c|c|c|c|c|}
\hline \multirow[b]{2}{*}{ Age $x$} & \multicolumn{5}{|c|}{ Female } & \multicolumn{5}{|c|}{ Male } \\
\hline & ${ }_{n} m_{x}$ & ${ }_{n} q_{x}$ & $l_{x}$ & ${ }_{n} L_{x}$ & $e_{x}$ & ${ }_{n} m_{x}$ & ${ }_{n} q_{x}$ & $l_{x}$ & ${ }_{n} L_{x}$ & $e_{x}$ \\
\hline 0 & 0.0045 & 0.0045 & 1000 & 995.9 & 78.2 & 0.0053 & 0.0052 & 1000 & 995.1 & 71.7 \\
\hline 1 & 0.0003 & 0.0013 & 995 & 3978.7 & 77.6 & 0.0004 & 0.0015 & 995 & 3975.5 & 71.1 \\
\hline 5 & 0.0002 & 0.0009 & 994 & 4968.7 & 73.7 & 0.0002 & 0.0012 & 993 & 4963.5 & 67.2 \\
\hline 10 & 0.0002 & 0.0010 & 993 & 4964.0 & 68.7 & 0.0003 & 0.0015 & 992 & 4956.8 & 62.3 \\
\hline 15 & 0.0004 & 0.0019 & 992 & 4957.2 & 63.8 & 0.0008 & 0.0038 & 991 & 4944.3 & 57.4 \\
\hline 20 & 0.0004 & 0.0022 & 990 & 4946.7 & 58.9 & 0.0012 & 0.0058 & 987 & 4920.6 & 52.6 \\
\hline 25 & 0.0005 & 0.0027 & 988 & 4934.3 & 54.0 & 0.0014 & 0.0070 & 981 & 4888.6 & 47.9 \\
\hline 30 & 0.0006 & 0.0029 & 985 & 4920.5 & 49.2 & 0.0016 & 0.0081 & 974 & 4852.3 & 43.2 \\
\hline 35 & 0.0008 & 0.0041 & 983 & 4903.9 & 44.3 & 0.0023 & 0.0114 & 966 & 4805.9 & 38.5 \\
\hline 40 & 0.0011 & 0.0054 & 979 & 4880.7 & 39.5 & 0.0031 & 0.0152 & 955 & 4743.0 & 33.9 \\
\hline 45 & 0.0019 & 0.0094 & 973 & 4845.8 & 34.7 & 0.0053 & 0.0261 & 941 & 4648.0 & 29.4 \\
\hline 50 & 0.0030 & 0.0148 & 964 & 4787.7 & 30.0 & 0.0080 & 0.0391 & 916 & 4496.3 & 25.1 \\
\hline 55 & 0.0049 & 0.0240 & 950 & 4695.3 & 25.4 & 0.0108 & 0.0528 & 880 & 4292.1 & 21.0 \\
\hline 60 & 0.0104 & 0.0509 & 927 & 4525.6 & 20.9 & 0.0224 & 0.1067 & 834 & 3963.7 & 17.1 \\
\hline 65 & 0.0177 & 0.0848 & 880 & 4225.4 & 16.9 & 0.0361 & 0.1661 & 745 & 3431.0 & 13.8 \\
\hline 70 & 0.0269 & 0.1263 & 805 & 3784.6 & 13.3 & 0.0499 & 0.2227 & 621 & 2771.8 & 11.0 \\
\hline 75 & 0.0355 & 0.1638 & 704 & 3248.3 & 9.8 & 0.0597 & 0.2605 & 483 & 2108.0 & 8.4 \\
\hline 80 & 0.1018 & 0.4081 & 588 & 2358.2 & 6.2 & 0.1281 & 0.4834 & 357 & 1347.6 & 5.5 \\
\hline 85 & 0.2723 & 1.0000 & 348 & 1279.1 & 3.7 & 0.3068 & 1.0000 & 184 & 601.1 & 3.3 \\
\hline
\end{tabular}

Note: Authors' calculations using data from the Kerala MARANAM Study and adjusted population estimates from the DHS Program (2020). 
Table A8 Life tables, 2017

\begin{tabular}{|c|c|c|c|c|c|c|c|c|c|c|}
\hline \multirow[b]{2}{*}{ Age $x$} & \multicolumn{5}{|c|}{ Female } & \multicolumn{5}{|c|}{ Male } \\
\hline & ${ }_{n} m_{x}$ & ${ }_{n} q_{x}$ & $l_{x}$ & ${ }_{n} L_{x}$ & $e_{x}$ & ${ }_{n} m_{x}$ & ${ }_{n} q_{x}$ & $l_{x}$ & ${ }_{n} L_{x}$ & $e_{x}$ \\
\hline 0 & 0.0054 & 0.0054 & 1000 & 995.1 & 77.9 & 0.0062 & 0.0062 & 1000 & 994.3 & 71.4 \\
\hline 1 & 0.0003 & 0.0013 & 995 & 3975.5 & 77.3 & 0.0004 & 0.0015 & 994 & 3971.8 & 70.9 \\
\hline 5 & 0.0002 & 0.0011 & 993 & 4964.1 & 73.4 & 0.0002 & 0.0012 & 992 & 4958.9 & 67.0 \\
\hline 10 & 0.0002 & 0.0011 & 992 & 4958.5 & 68.5 & 0.0003 & 0.0015 & 991 & 4952.1 & 62.1 \\
\hline 15 & 0.0004 & 0.0022 & 991 & 4951.0 & 63.6 & 0.0008 & 0.0040 & 990 & 4939.0 & 57.2 \\
\hline 20 & 0.0005 & 0.0025 & 989 & 4939.0 & 58.7 & 0.0011 & 0.0056 & 986 & 4915.2 & 52.4 \\
\hline 25 & 0.0005 & 0.0024 & 986 & 4926.4 & 53.8 & 0.0013 & 0.0065 & 980 & 4884.8 & 47.7 \\
\hline 30 & 0.0006 & 0.0030 & 984 & 4913.4 & 49.0 & 0.0016 & 0.0079 & 974 & 4850.3 & 43.0 \\
\hline 35 & 0.0009 & 0.0043 & 981 & 4896.1 & 44.1 & 0.0023 & 0.0112 & 966 & 4805.2 & 38.3 \\
\hline 40 & 0.0012 & 0.0058 & 977 & 4871.4 & 39.3 & 0.0032 & 0.0158 & 955 & 4741.8 & 33.7 \\
\hline 45 & 0.0020 & 0.0099 & 971 & 4834.6 & 34.5 & 0.0051 & 0.0254 & 940 & 4647.1 & 29.2 \\
\hline 50 & 0.0030 & 0.0150 & 962 & 4774.6 & 29.8 & 0.0078 & 0.0385 & 916 & 4498.1 & 24.9 \\
\hline 55 & 0.0051 & 0.0250 & 947 & 4679.5 & 25.2 & 0.0111 & 0.0542 & 881 & 4292.2 & 20.8 \\
\hline 60 & 0.0108 & 0.0525 & 924 & 4504.6 & 20.8 & 0.0230 & 0.1094 & 833 & 3957.4 & 16.8 \\
\hline 65 & 0.0186 & 0.0889 & 875 & 4193.1 & 16.8 & 0.0377 & 0.1731 & 742 & 3406.6 & 13.5 \\
\hline 70 & 0.0278 & 0.1303 & 797 & 3739.1 & 13.2 & 0.0533 & 0.2362 & 614 & 2717.4 & 10.8 \\
\hline 75 & 0.0353 & 0.1630 & 693 & 3203.7 & 9.8 & 0.0596 & 0.2601 & 469 & 2046.4 & 8.4 \\
\hline 80 & 0.1030 & 0.4122 & 580 & 2322.3 & 6.2 & 0.1316 & 0.4933 & 347 & 1300.2 & 5.4 \\
\hline 85 & 0.2724 & 1.0000 & 341 & 1252.1 & 3.7 & 0.3090 & 1.0000 & 176 & 568.6 & 3.2 \\
\hline
\end{tabular}

Note: Authors' calculations using data from the Kerala MARANAM Study and adjusted population estimates from the DHS Program (2020). 
Table A9 Crude death rate estimates adjusted for migration (2011); by sex

\begin{tabular}{lccc}
\hline & Female & Male & Total \\
\hline Crude death rate (CDR) $^{\mathrm{a}}$ & 5.93 & 8.64 & 7.23 \\
CDR excluding migrants $^{\mathrm{b}}$ & 5.99 & 8.70 & 7.29 \\
CDR excluding recent migrants $^{\mathrm{c}}$ & 5.89 & 8.54 & 7.16 \\
\hline
\end{tabular}

${ }^{a}$ Census populations, all civil registration system deaths.

${ }^{b}$ Deaths are for people with permanent residence in Kerala, and population counts exclude people born outside Kerala.

${ }^{\mathrm{c}}$ Deaths are for people with permanent residence in Kerala, and population counts exclude people whose last residence was outside Kerala in the last year. 
Table A10 Standard deviation, mortality rate $\left({ }_{n} m_{x}\right), 2006-2017$

\begin{tabular}{cccccc}
\hline & \multicolumn{2}{c}{ CRS } & & \multicolumn{2}{c}{ SRS } \\
\cline { 2 - 3 } \cline { 5 - 6 } Age $x$ & Female & Male & & Female & Male \\
\hline 0 & 1.38 & 1.88 & & 1.13 & 1.09 \\
1 & 0.08 & 0.08 & & 0.21 & 0.19 \\
5 & 0.04 & 0.04 & & 0.09 & 0.11 \\
10 & 0.03 & 0.02 & & 0.11 & 0.12 \\
15 & 0.04 & 0.07 & & 0.18 & 0.27 \\
20 & 0.08 & 0.06 & & 0.28 & 0.32 \\
25 & 0.07 & 0.08 & & 0.30 & 0.43 \\
30 & 0.07 & 0.07 & & 0.26 & 0.45 \\
35 & 0.09 & 0.17 & & 0.25 & 0.42 \\
40 & 0.12 & 0.29 & & 0.50 & 0.77 \\
45 & 0.18 & 0.40 & & 0.55 & 0.88 \\
50 & 0.24 & 0.51 & & 1.19 & 0.96 \\
55 & 0.40 & 0.82 & & 0.79 & 1.20 \\
60 & 0.98 & 1.76 & & 1.44 & 1.81 \\
65 & 0.80 & 2.15 & & 1.73 & 2.63 \\
70 & 1.59 & 3.45 & & 4.91 & 6.66 \\
75 & 1.61 & 2.97 & & 8.81 & 6.50 \\
80 & 7.64 & 8.10 & & 11.68 & 13.54 \\
85 & 31.51 & 31.92 & & 29.63 & 36.72 \\
\hline & & & & \\
\hline & & & &
\end{tabular}

Note: Authors' calculations using data from the Kerala MARANAM Study and adjusted population estimates from the DHS Program (2020). CRS: Civil Registration System. SRS: Sample Registration System. 